\title{
MONEDA OFICIAL I DIVERSITAT MONETÀRIA A CATALUNYA A LA PRIMERA MEITAT DEL SEGLE XIII: EL CAS DE VIC
}

\author{
RAFEL GINEBRA I MOLINS \\ Arxiu Episcopal de Vic \\ SUMARI
}

1. Els diferents numeraris a ACF-1: 1. Moneda barcelonesa de doblenc.1.2. moneda melgoresa.- 1.3. Morabatins.- 1.4. Moneda de quatern.- 1.5. Besants.- 1.6. Masmudines.- 1.7. Marcs d'argent.- 1.8. Millaresos.- 1.9. Rals coronats.- 1.10. Conclusió de la revisió dels tipus de moneda.- 2. Equivalències monetàries.

Els estudis sobre moneda medieval, sobretot pel segle XIII, són estudis numismàtics, més o menys documentats, que s'han basat especialment o bé en l'estudi de peces numismàtiques o bé en documentació relativa a encunyacions, i sobretot a aquelles fetes pels poders públics de l'àmbit català amb potestat per a fer-ho, cosa que dóna una visió parcial i incompleta del panorama monetari real. L'anàlisi de les monedes que apareixen a la documentació, de les monedes en què s'estableixen els tractes dels documents, deixa constància de la presència i del pes relatiu no tan sols de les monedes encunyades per la corona catalana, sinó d'altres monedes foranes que també circulen en el mateix àmbit.

Partim, per aquest estudi, de les referències a moneda en els 3.308 documents que conté el primer volum de l'Arxiu de la Cúria Fumada de Vic, que van des de principis de setembre de 1230 fins a principis de desembre de 1233 , que permeten obtenir una imatge molt precisa per aquest periode concret i que, completats amb altra documentació vigatana permeten

"Anuario de Estudios Medievales", 26 (1996) 
aproximar-se de forma coherent el panorama monetari especialment pel periode dels anys 20 als anys 50 d'aquest segle'.

Dels 3.308 documents que proporciona el primer volum notarial de Vic, que és el de major entitat dels primers volums notarials catalans conservats, n'hi ha 1.022 en els quals no hi ha cap referència a moneda. En la major part dels casos la causa és el propi tipus de document. En documents com procures, donacions, definicions, compromisos etc. és lògic, per la seva pròpia naturalesa, que no hi hagi cap referència a moneda, i fins $i$ tot en documents com vendes o establiments no és inhabitual que tampoc n'hi hagi i que el preu o el pagament s'estableixi en gra o en general en espècie, o en parts d'esplets; en altres documents la causa que no hi puguem considerar referència a moneda és senzillament el seu mal estat o deteriorament, que els fa parcialment legibles.

En tota la resta de documents, 2.286, hi ha referència a moneda, ja sigui a una sola moneda o tipus de moneda, o a més d'un. En aquests casos en què hi ha referència a diverses monedes lògicament les contemplem totes, de manera que globalment, els 3.308 documents del volum, o millor dit els 2.286 en què hi consta referència a moneda, donen 2.359 referències a moneda $^{2}$.

\section{ELS DIFERENTS NUMERARIS A ACF-1}

Vegem en primer lloc quines són les monedes documentades a ACF-1 i el nombre de vegades que apareixen; després farem una petita revisió de cada un d'aquests numeraris, i finalment ens referirem a les poques equivalències entre diferents monedes que proporciona el volum.

\footnotetext{
'Aquest article és una reelaboració de l'apartat que vam dedicar a aquest tema en la tesi doctoral que amb el títol Economia i societat a la Catalunya interior als inicis de la baixa Edat Mitjana. Vic 1230-1233, vam llegir a la Facultat de Geografia i Història de la Universitat de Barcelona el juny de 1996.

${ }^{2} \mathrm{El}$ que tractem en aquest apartat són els tipus de moneda que apareixen en cada document. En els documents en què es fa referència a la mateixa quantitat $i$ moneda primer com a total $i$ després com a parts (com és el cas, per exemple, dels debitoris, en què després d'establir-se la quantitat total s'estableixen les parts en què s'ha de fer el pagament), hem comptabilitzat lògicament només una referència. La diferència entre el nombre de documents amb referència a moneda $\mathrm{i}$ el nombre de referències a moneda és degut als documents en què hi consta més d'un tipus de numerari.
} 
Presentem en primer lloc en una taula els diferents tipus de moneda $\mathrm{i}$ el nombre de recurrències. A banda del nombre total en el volum, hi presentem el recompte fent talls de 1000 documents per a considerar la possibilitat d'una evolució de les proporcions en els tres anys i tres mesos que abasta el volum. Els talls de 1000 documents coincideixen gairebé amb periòdes d'un any: els documents 1-1000 van de 4 de setembre de 1230 a 26 de setembre de 1231; els documents 1001-2000 van de 26 de setembre de 1231 a 21 de setembre de 1232; els documents 2001-3000 van de 21 de setembre de 1232 a 19 d'agost de 1233 , i finalment, els restants 308 documents van del 19 d'agost al 3 de desembre de 1233 .

\begin{tabular}{|c|c|c|c|c|c|}
\hline & ACF-1 & $\begin{array}{l}\text { doc.1- } \\
1000\end{array}$ & $\begin{array}{l}1001- \\
2000\end{array}$ & $\begin{array}{l}2001- \\
3000\end{array}$ & $\begin{array}{l}3001- \\
3308\end{array}$ \\
\hline $\begin{array}{l}\text { NO CONSTA- } \\
/ \text { IL } \cdot \text { LEGIBLE }\end{array}$ & 1022 & 302 & 321 & 300 & 99 \\
\hline $\begin{array}{l}\text { AMB MONEDA/- } \\
\text { MONEDES }\end{array}$ & 2286 & 698 & 679 & 700 & 209 \\
\hline $\begin{array}{l}\text { REFERÈNCIES A } \\
\text { MONEDA }\end{array}$ & 2359 & 715 & 703 & 723 & 218 \\
\hline DOBLENC & 1945 & 584 & 599 & 588 & 174 \\
\hline MELGORESA & 162 & 37 & 39 & 66 & 20 \\
\hline MORABATINS & 91 & 33 & 25 & 24 & 9 \\
\hline QUATERN & 72 & 16. & 25 & 23 & 8 \\
\hline BESANTS & 67 & 34 & 11 & 18 & 4 \\
\hline MASMUDINES & 13 & 8 & 2 & 2 & 1 \\
\hline MARCS & 7 & 3 & & 2 & 2 \\
\hline MILLARESOS & 1 & & 1 & & \\
\hline RALS CORONATS & 1 & & 1 & & \\
\hline
\end{tabular}


La taula és prou eloqüent. Vegem encara, però, el que signifiquen aquests valors en forma gràfica i percentual. Comencem primer per la proporció entre documents amb moneda i documents sense moneda:

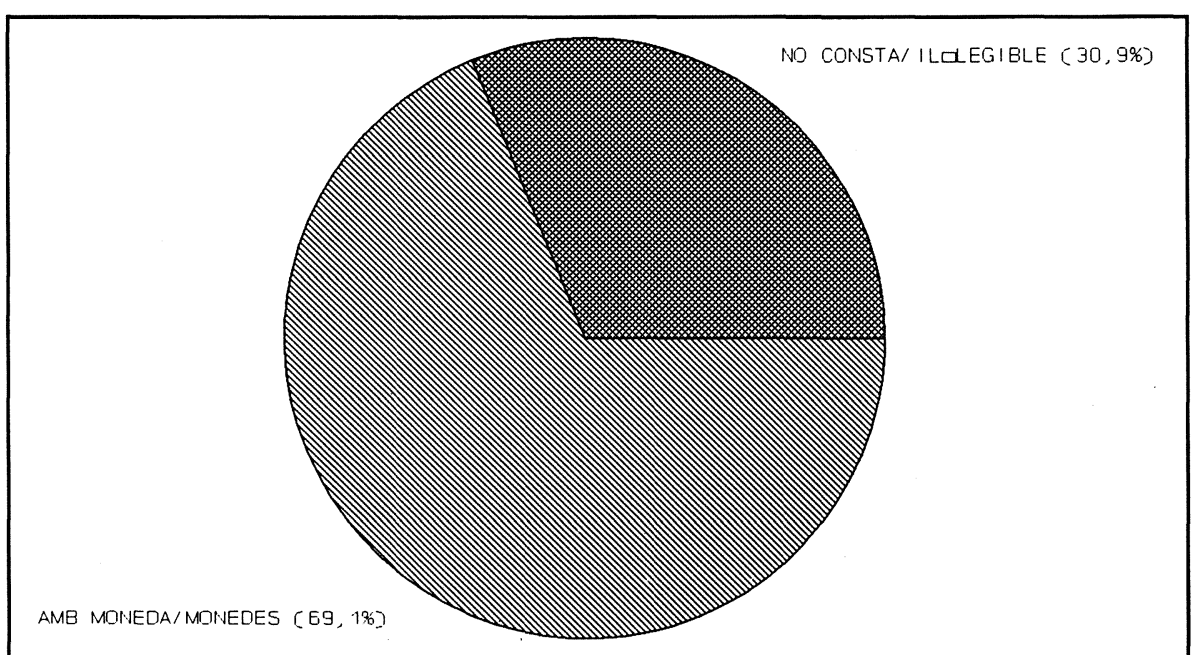

1. Proporció dels documents d'ACF-1 en què hi consta moneda.

La proporció es manté estable al llarg del volum, de manera que els percentatges de documents amb referència a un o més numeraris en els successius talls que hem establert són, respectivament, de 69'8, 67'9, 70 i 67 '9.

Vegem ara, descartant els documents en què no hi consta moneda $\mathrm{i}$ tenint en compte només les referències a moneda, la distribució i percentatge dels diferents numeraris (Gràfic. núm. 2): 


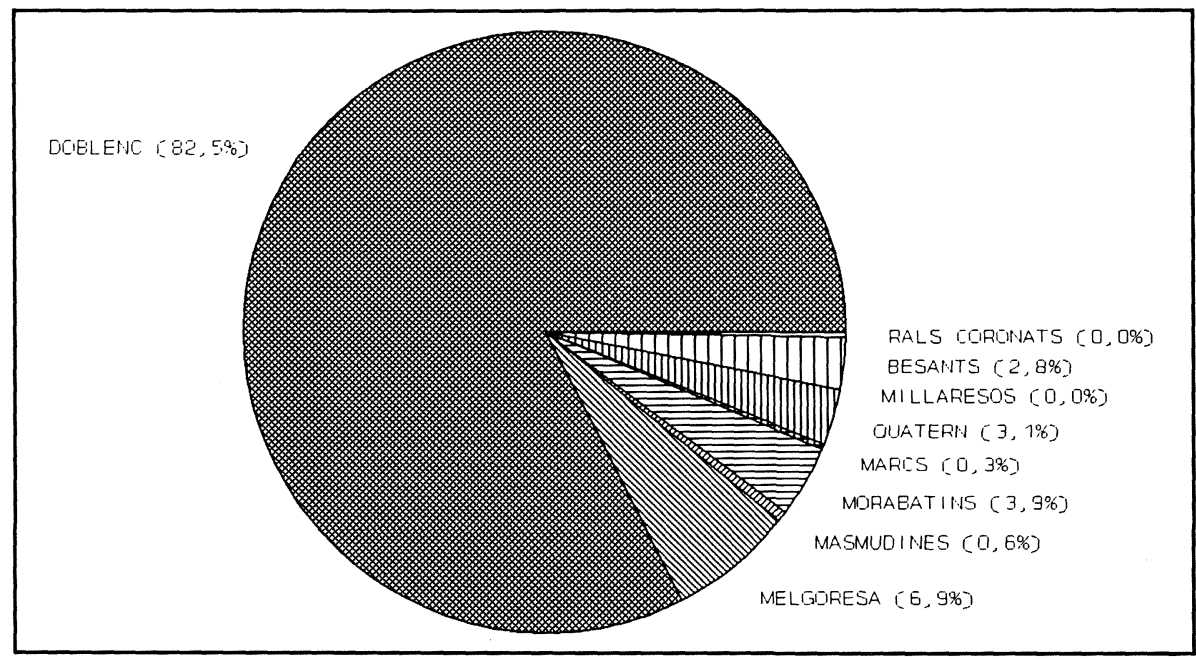

2. Proporció dels diferents tipus de moneda a ACF-1.

L'evolució en els quatre talls que hem fet en els documents del volum seria la que es pot observar en els gràfics núms. 3, 4, 5 i 6.

Tot i que en sentit estricte el marc no és un tipus de moneda sinó una unitat de pes, conscientment hem inclòs els marcs d'argent pel fet que en els casos en què apareixen en la documentació és sempre com a moneda de compte, absolutament equiparable a les monedes pròpiament dites, monedes que sovint, per altra banda, són també només unitats de compte sense existència física, com en el cas potser més obvi dels sous o de les lliures. De fet, en general totes les monedes en què es fan les apreciacions o transaccions cal considerar-les en certa manera monedes de compte, sense que signifiqui que els pagaments es fessin o s'haguessin de fer en el numerari corresponent. De la mateixa manera que els pagaments no es podien fer en sous perquè no n'existien, és probable que els pagaments fixats en morabatins, marcs o qualsevol altra unitat no es fessin necessàriament en aquestes unitats sinó en la quantitat equivalent del numerari disponible.

Feta aquesta petita precisió, i tornant als valors, com es pot veure, el Vic de finals del primer terç del segle XIII està immers de forma clara en 

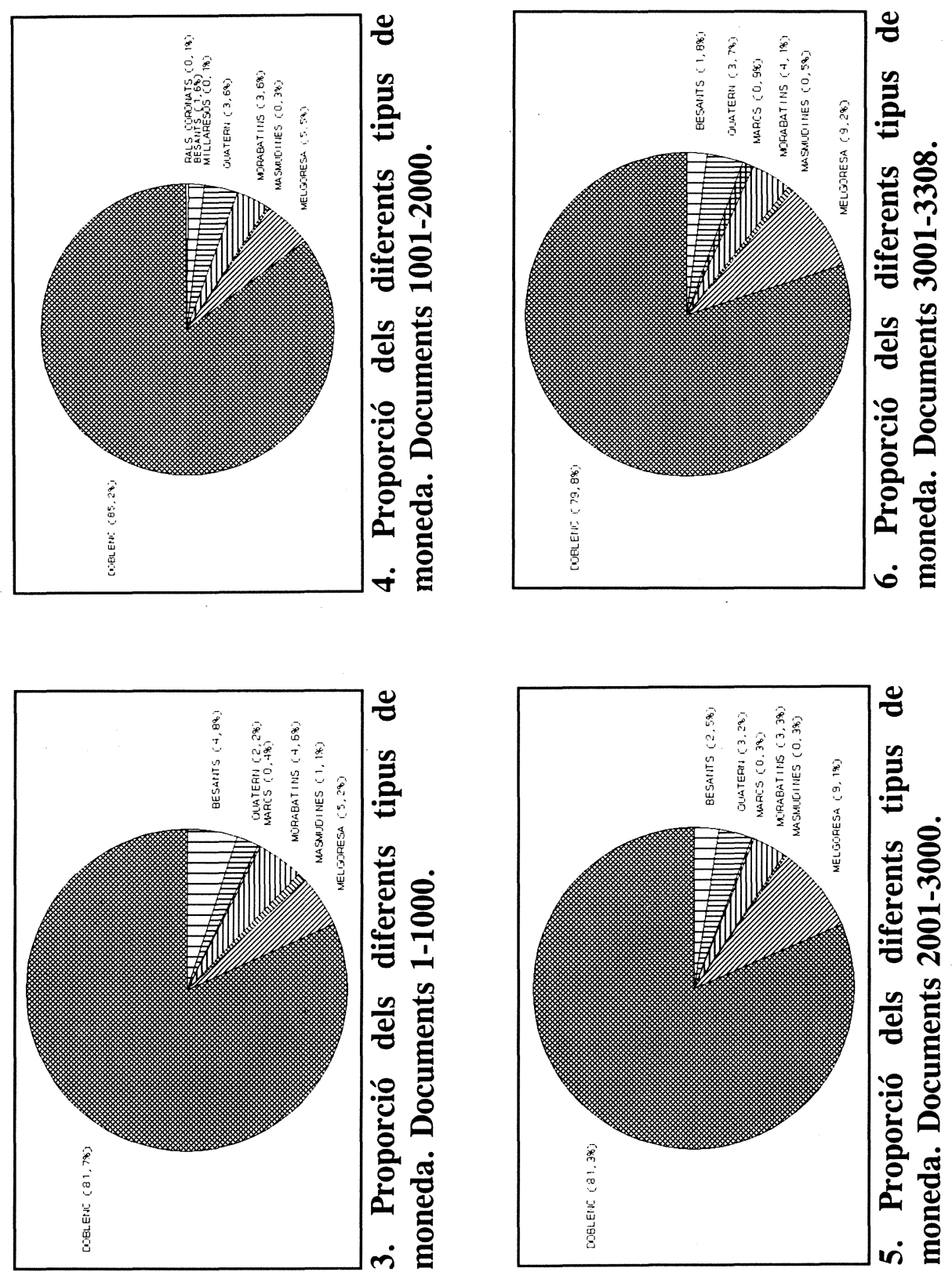
l'òrbita de la moneda barcelonesa de doblenc, que representa el $82,5 \%$ de les transaccions o valoracions, però no deixen d'haver-hi recurrències, en alguns casos bastant significatives, d'altres monedes, fins un total de 9 monedes diferents coexistint en el mateix espai i moment.

Les diferències o les petites oscil-lacions de les diferents monedes quant a percentatges en els quatre talls contemplats no semblen significatives ni semblen indicar una línia d'evolució clara. Aquesta estabilitat resulta raonable tenint en compte que es tracta de tres anys successius i que les pautes d'utilització de diferents numeraris es mouen en general seguint tendències més lentes. Només situacions puntuals i més o menys excepcionals, normalment motivades per circumstàncies alienes al món econòmic com a tal, poden produir canvis dràstics o sobtats en el panorama monetari, ja siguin circumstàncies polítiques, bèl-liques o de fiscalitat pública. En aquest sentit, el grau d'estabilitat seria per exemple probablement molt diferent deu anys abans, quan hi ha la "ruptura" produida per l'inici de l'encunyació de la moneda de doblenc, que s'imposa a més, almenys teòricament, com a moneda obligatòria. A diferència dels primers anys trenta, en els tres primers anys vint del segle sí que probablement s'hi veuria una evolució més clara, marcada per la aparició i ascens de la moneda de doblenc. Tot i així, la situació que trobem deu anys més tard permet pensar que la introducció de la moneda de doblenc, que teòricament hauria d'haver donat lloc a una discontinuitat radical en el panorama monetari, malgrat les pretensions de la corona $\mathrm{i}$ com resulta comprensible, més que en forma de ruptura es va fer en forma d'inflexió ja que deu anys mès tard encara hi ha presència de la moneda substituida pel doblenc, numerari que al capdevall deixa un $17,5 \%$ a altres monedes.

De fet, més que la variació de la utilització de les diferents monedes al llarg del curt periode que representa els tres anys i tres mesos del volum, el que resulta interessant és comprovar fins quin punt l'ús d'aquestes monedes resulta indistint o fins quin punt cada un dels numeraris està vinculat de forma predominant a activitats o àmbits concrets. De forma nteressant i d'altra banda lògica, el que es constata és una diferent proporció

Is diferents tipus de monedes en les diferents tipologies documentals. En . Lest sentit ens sembla interessant reflectir els resultats de les anàlisis de les monedes en les tipologies més significatives i característiques. 


\begin{tabular}{|c|c|c|c|c|c|c|}
\hline & Debitoris & Àpoques & \begin{tabular}{|l} 
Establiments \\
Preus
\end{tabular} & \begin{tabular}{|l|} 
Establiments \\
Censos
\end{tabular} & $\begin{array}{l}\text { Societ.- } \\
\text { Coman- } \\
\text { des }\end{array}$ & $\begin{array}{l}\text { Vendes } \\
\text { de } \\
\text { terres }\end{array}$ \\
\hline Docs. amb moneda & 735 & 107 & 113 & 41 & 55 & 227 \\
\hline núm. referències & 739 & 113 & 113 & 41 & 58 & 227 \\
\hline Doblenc & 600 & 68 & 110 & 15 & 30 & 221 \\
\hline Melgoresa & 103 & 4 & & & 15 & 1 \\
\hline Morabatins & 7 & 15 & 2 & 4 & & 4 \\
\hline Quatern & & 4 & & 16 & 1 & \\
\hline Besants & 24 & 9 & & & 10 & 1. \\
\hline Masmudines & 2 & 2 & 1 & 6 & 1 & \\
\hline Marcs & 1 & 1 & & & 1 & \\
\hline (indeterminat) & 2 & & & & & \\
\hline
\end{tabular}

Presentem un cop més de forma gràfica les proporcions i percentatges que aquestes xifres representen (Gràfics núms. 7, 8, 9, 10,11 i 12).

Cal tenir en compte, a l'hora d'interpretar les gràfiques, la diferent base numèrica de què deriven. Com més petit és el número de documents més variació percentual pot portar una petita variació casual o circumstancial en el número de referències. En tot cas es tracta, però, de tots els documents, de les respectives tipologies, que consten al volum. De fet, per mitigar les distorsions derivades de bases petites, hem agrupat, per exemple, totes les referències relacionades amb societats i comandes, que inclouen en realitat quatre tipologies ${ }^{3}$.

${ }^{3}$ Constitucions de Societats, Rebuts en Societat, Rebuts en Comanda i Comandes. Si consideressim algunes d'aquestes tipologies separades, el resultat seria encara més dràstic que el que reflecteix el cinquè gràfic. En el cas de les constitucions de societats, per exemple, els documents en melgoresa tripliquen els documents en doblenc, però es tracta d'una tipologia amb només set referències. 

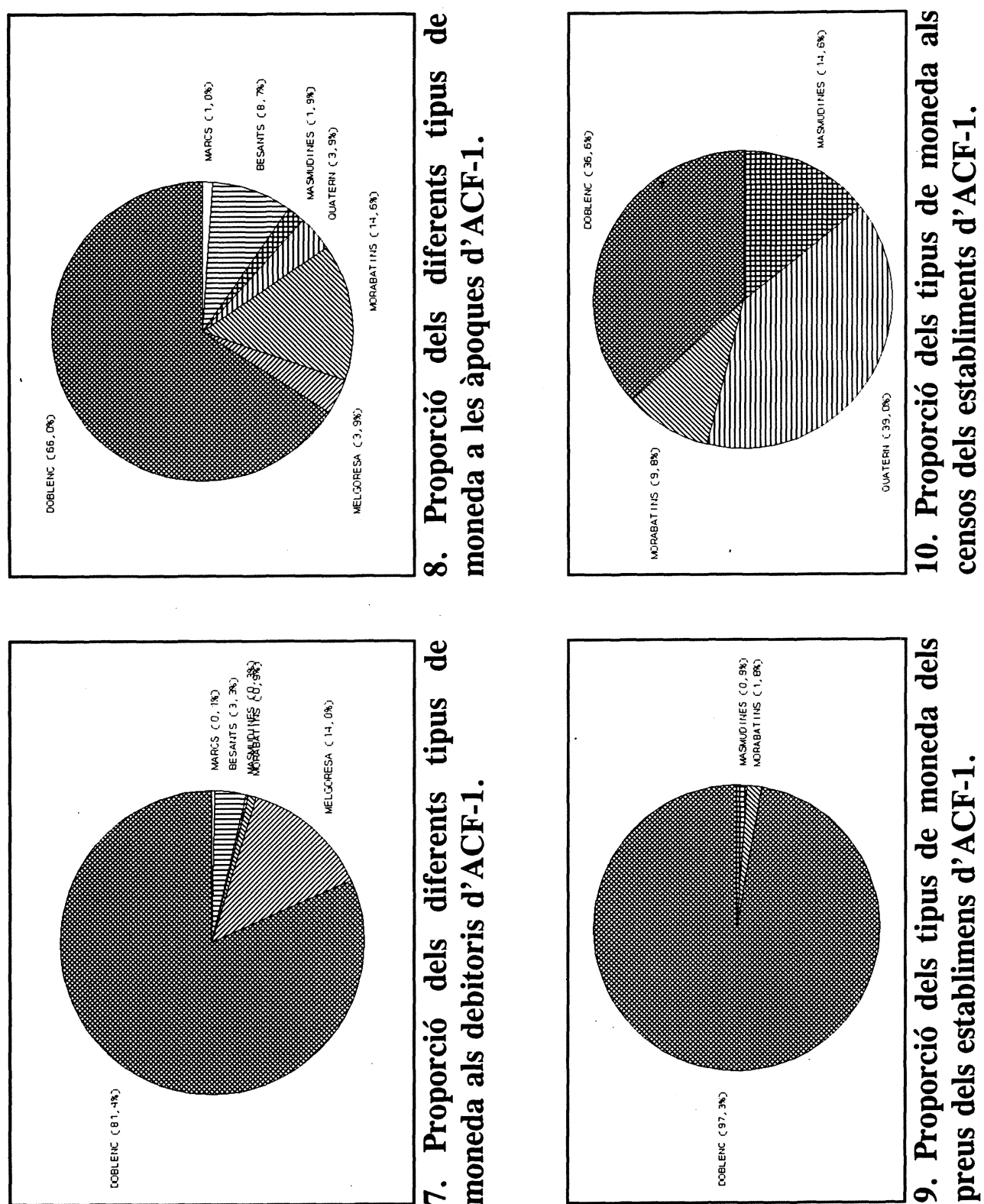


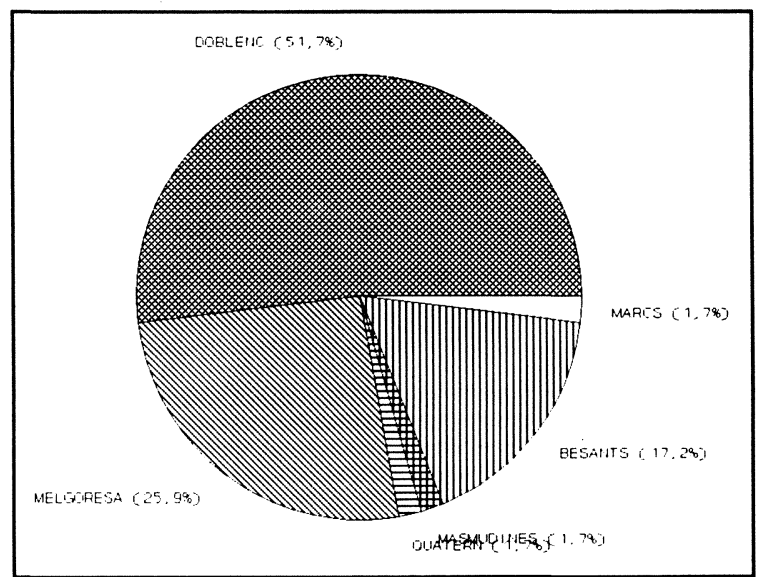

11. Proporció dels tipus de moneda a les societats i comandes d'ACF-1.

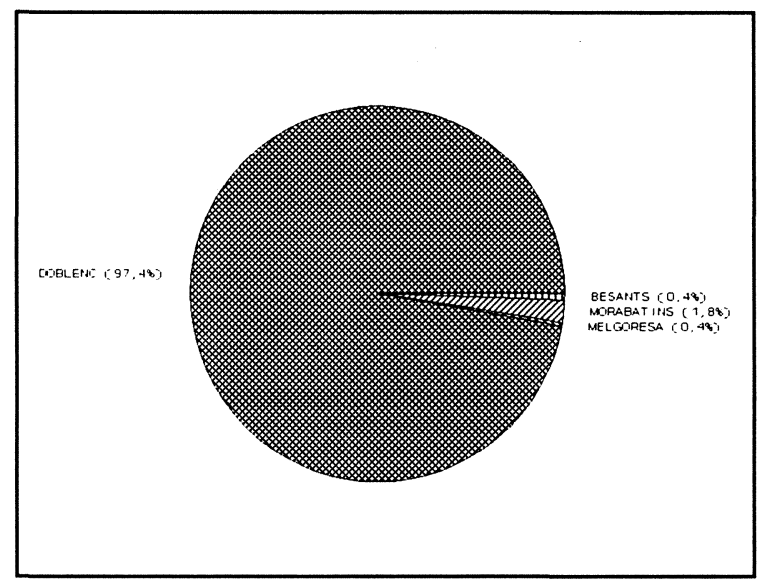

12. Proporció dels tipus de moneda a les vendes de terres d'ACF-1. 
Totes aquestes gràfiques per tipologies tenen interessants peculiaritats en relació amb la gràfica general de les proporcions de monedes al volum. A la tipologia que recull més documents, els debitoris, el percentatge de doblenc és practicament el mateix que el general del volum $(81,4 \%$ i $82,5 \%$ respectivament), però en els altres numeraris destaca la proporció doble de la moneda melgoresa, en detriment especialment de les referències a morabatins i a moneda de quatern en la qual no hi ha ni un sol debitori. En les àpoques, en canvi, tot $\mathrm{i}$ que es podria esperar que el comportament fos paral-lel al dels debitoris, a banda de baixar el percentatge de doblenc fins un $66 \%$, els morabatins suposen un $14,6 \%$ i els besants un $8,7 \%$ mentre que la melgoresa cau a un 3,9\% sense que s'hi pugui entreveure una explicació lògica; el quatern té un percentage lleument més elevat que el global del volum.

Més dràstics encara són els quatre darrers gràfics. És de notar, pel que fa a establiments, l'absoluta diferència pel que fa a tipus monetaris entre les quantitats que fan referència al preu de l'establiment $i$ les quantitats que fixen el cens que haurà de pagar el receptor. Si els preus són en el 97,3\% dels establiments en moneda de doblenc i la resta són en morabatins i masmudines, els censos representen la distribució que més s'allunya de la gràfica general del volum ja que el doblenc queda reduit a un $36,6 \%$, morabatins i masmudines suposen més d'un $24 \%$ (i encara constituint les masmudines un $14 \%$ quan en tot el volum no suposen més d'un $0,6 \%$ ), i, sobretot, el quatern, moneda residual en la majoria de tipologies i àmbits, constitueix en els censos dels establiments la moneda majoritària, amb un $39 \%$. Aquesta insòlita distribució de numeraris ha d'estar relacionada amb la pròpia condició o tendència consuetudinària i continuïsta dels censos, la tendència a perllongar de forma més o menys inercial els censos que es fixen, no tan sols pel que fa al valor sinó pel que fa a la moneda. Pel fet de tractar-se de càrregues o exaccions indefinides en el temps poden tenir una evolució molt més lenta, i reflectir esquemes monetaris absolutament anacrònics, com és aquest cas en què la moneda que és teòricament la moneda corrent representa sols un $36 \%$ mentre que una altra moneda que és teòricament fora d'ús des de l'aparició del doblenc, el quatern, representa ni més ni menys que un 39\%. Probablement, l'esquema que reprodueixen els censos dels establiments en aquest periode 1230-1233 és molt semblant a l'esquema monetari general que podriem haver trobat vuit o deu anys abans. Si bé els altres àmbits s'han adaptat més al panorama monetari determinat 
de facto per la moneda de doblenc, els censos segueixen encara reproduint pautes anteriors, un esquema arcaic, anacrònic.

Ens sembla també interessant fer notar que la presència de masmudines i morabatins en els censos dels establiments junt a la moneda de quatern pot fer pensar en un caràcter en certa manera també anacrònic d'aquestes monedes, que malgrat ser monedes foranes ocupen espais molt importants en l'àmbit més conservador o immovilista de l'economia, els censos. Per contra, la inexistència de besants i de moneda melgoresa en els censos dels establiments semblaria indicar un caràcter més innovador en l'ús d'aquestes monedes. Aquest caracter es confirma en comprovar quin és l'àmbit en què aquests dos numeraris tenen un major pes. La melgoresa, que suposa menys d'un $7 \%$ en el conjunt del volum, suposa més d'un $14 \%$ en els debitoris, que estan vinculats amb activitat econòmica comercial i financera, però, de forma encara més significativa, suposa pràcticament un $26 \%$ de les referències a moneda en els documents relacionats directament i explícitament amb societats i comandes. També en aquest mateix darrer àmbit els besants que al conjunt del volum suposen un $2,8 \%$ de les referències a moneda passen a representar un $17,2 \%$. Per contra, en aquest àmbit purament comercial la moneda de doblenc representa només un $51,7 \%, 30$ punts menys que el percentatge general del volum. Tractant-se d'un àmbit comercial sovint explícitament relacionat amb comerç exterior resulta lògic que es doni un major pes de moneda estrangera, però recordem que els morabatins i masmudines que trobàvem en els censos dels establiments són també moneda estrangera $i$, mentre que les masmudines tenen una presència residual en els afers relacionats amb societats i comandes, els morabatins castellans en són absolutament absents. Això reflecteix d'alguna manera una evolució en l'ús de tipus de moneda, que, tanmateix, i és això el que resulta interessant, ha d'estar relacionat amb una evolució en el món econòmic comercial i en l'àmbit geogràfic d'aquestes relacions comercials. Aquesta evolució seria marcada, alhora, per una substitució de monedes i per un canvi en les àrees de destí, sent morabatins i masmudines -monedes castellanes i mussulmanes respectívament-, substituïdes per melgoresa - moneda ultrapirinenca- $\mathrm{i}$ besants d'argent - moneda musulmana-. Aquesta substitució ha d'estar relacionada amb aspectes de valor intrínsec i de prestigi monetari -és sols aquest valor i prestigi el que fa que una moneda sigui acceptada internacionalment, més enllà del marc polític originari-, i amb aspectes de reorientació dels destins comercials. 
En certa manera el gràfic dels censos d'establiments i el de societats i comandes representen el passat i el futur en relació amb la distribució monetària general que ens dóna el volum pel primer trienni de la quarta dècada del segle XIII: el primer seria l'esquema que representa un panorama monetari ja depassat — predomini de quatern i importància del doblenc pel que fa a monedes locals, i pes important de morabatins i masmudines com a moneda forana-comercial-, i el segon seria l'esquema que representa un panorama monetari del futur, o del present més innovador com és el món econòmic articulat amb el comerç exterior - doblenc reduit al $51 \%$ pel seu poc valor que el fa inútil pel comerç més enllà de l'àmbit local, i quatern residual, pel que fa a monedes pròpies, i masmudines residuals substituides per la ultrapirinenca moneda melgoresa i pels besants d'argent musulmans pel que fa a la moneda estrangera-.

Alguns àmbits, però, no es mouen només amb critèris de prestigi monetari o de utilitzabilitat de moneda, i pel seu àmbit estrictament local s'han de cenyir més a la normativa teòrica fixada pels poders públics. De la mateixa manera que hem vist que el $97,3 \%$ dels preus dels establiments -negocis de caràcter estrictament local- es feien en doblenc, que és al capdevall la moneda pròpia, corrent i obligatòria per a l'ús local, i que la resta es feia precisament en morabatins i masmudines, també en el cas de les vendes de terres - transaccions de caràcter igualment local-, el 97,4\% són en moneda de doblenc i la segona moneda són els morabatins, encara que en aquest cas apareixen sengles referències, úniques, a melgoresa i a besants.

Després d'aquesta anàlisi del panorama monetari que hem fet tant per periodes com per tipologies i després d'haver anat esmentant els diferents tipus de moneda, no podem eludir fer una revisió d'aquests tipus de moneda tot $\mathrm{i}$ que lògicament els hem considerat ja coneguts.

Seguirem l'ordre marcat per la freqüència de les monedes.

\subsection{Moneda barcelonesa de doblenc}

Sota el regnat de Jaume I, en principi hi ha emissions aragoneses de moneda dolenta, de baixa llei, com a solució habitual per a fer front a dificultats financeres puntuals. En aquest cas les dificultats són derivades dels deutes deixats pel seu pare, el rei Pere I mort a Muret. La mala qualitat de la moneda fa que el rei es vegi obligat a retirar-la davant la pressió dels aragonesos. El 1222, però, s'inicia l'emissió d'un nou tipus de moneda, la moneda de doblenc, que té, com el nom indica, dues parts de plata sobre les 
dotze de la plata pura, la meitat que la de quatern, cosa que significa un percentatge del $16,6 \%$. La creació d'aquesta moneda de nou ve motivada pels deutes de la corona, i prova d'això és que malgrat que la moneda val intrínsicament la meitat que la moneda de quatern, la corona intenta establir el canvi fixant una equivalència de 12 diners de quatern igual a 18 diners de doblenc, quan l'equivalència segons el valor havia de ser de 12 diners de quatern igual a 24 de doblenc. S'intenta, doncs, donar al doblenc un valor legal molt més elevat de l'intrínsec, i s'imposa el seu ús de forma obligatòria. De fet, però, en contra d'aquest intent va prevaldre el valor real de la nova moneda, i aquesta fou estimada com equivalent a la meitat del valor del quatern ${ }^{4}$.

Sobre la data d'encunyació de la moneda de doblenc, Botet en el text de la seva obra ${ }^{5}$ parla de 1221 , i avala l'encunyació en aquest any remetentse als comptes donats per Pere moneder, Arnau de Merola i Guillem de Lacerà el dia 1 de febrer de 1222 de la moneda encunyada del 22 d'agost fins el 22 de desembre de 1221. Tanmateix, aporta el document en l'apèndix de la seva obra ${ }^{6}$, i creiem que hi pot haver un error de còmput. El document comença, efectivament, "Anno domini MCC vicesimo secundo, prima die februarii"; parla de "omnibus fusionibus que facte fuerunt ab XI kelendis septembris usque in tercio Kelendas Novembris", i cap al final del document parla de "illo albarano magno quod fuit factum Ilerde, anno domini MCC vicesimo secundo, VI idus septembris". El fet que parli de kalendas de setembre i de novembre i que el document es digui de 2 de febrer de 1222 podria fer pensar que les encunyacions havien tingut lloc el 1221 , però la referència explícita al 6 idus de setembre de 1222 com a data pretèrita a l' 1 de febrer de 1222 que encapçala el document dóna una de les claus de la interpretació: el document és datat segons còmput de l'Encarnació, amb canvi d'any el 25 de març. Això encara no resol el problema ja que segons es desprèn d'altres passatges de la seva obra Botet considera vigent, dins el còmput de l'Encarnació, la variant pisana ${ }^{7} \mathrm{i}$ en aquest cas el document seria realment d' 1 de febrer de 1222 i es referiria a encunyacions

\footnotetext{
${ }^{4} J$ Joaquim BOTET I Sisó, Les Monedes Catalanes, II, Barcelona, 1909, pp. 38-39.

${ }^{5}$ BOTET I SISÓ, Les monedes, II, p. 38.

${ }^{6}$ BoteT I Sisó, Les monedes, III, p. 240, núm. III.

${ }^{7}$ Veure, per exemple, BOTET I Sisó, Les monédes, II. p. 47; En parlar de la taula de canvi establerta per Jaume I a València la situa al maig de 1246 que diu equivalent a maig del 1247 de l'any de l'Encarnació (erròniament 1347 al text).
} 
de 1221 , però altres autors consideren vigent la variant florentina ${ }^{8}$ amb canvi també el 25 de març però de l'any següent, i aquesta sembla ser la tendència actual, i en aquest cas la data de 1 de febrer de 1222 correspon al 1 de febrer de 1223 del còmput modern, i les restants dates d'agost, octubre i de setembre de 1222 són efectivament de 1222 . Aquest any és el que dóna Crusafont com a inici de l'encunyació de doblenc ${ }^{9}$, i tot deixant constància dels possibles qüestionaments de la data és aquesta la que prendrem.

En qualsevol cas, la moneda de doblenc és de fet la moneda dels comtats catalans des de la seva encunyació el 1222 en substitució de la de quatern reial i fins la seva substitució el 1257 per la de tern, i és per tant la moneda oficialment en curs en el marc i l'època que estem tractant, i això és efectivament el que reflecteixen els documents del volum. De les 2.360 monedes esmentades, com hem dit, 1945 , un $82,5 \%$, corresponen a moneda de doblenc. Surt esmentada als documents com "monete de duplo", "monete barchinonense de duplo", "monete barchinonense", "monete barchinonense curribilis", "monete barchinonense curribilis de duplo", "denariorum barchinonensium, monete curribilis" i altres variants. Només en dos casos es parla de "bone monete curribilis de duplo". El fet que sigui la moneda corrent i majoritària fa que sovint no es precisi que és doblenc i que es parli solament de solidos, sense que hi hagi cap dubte que quan es fa servir aquesta sola expressió es tracta de moneda de doblenc ${ }^{10}$.

${ }^{8}$ Aquest és el còmput que s'ha considerat aplicat als volums notarials catalans del segle XIII. Cf. J. M. Pons Guri, De l'escrivent al notari i de la "charta" a l'instrument. Recepció dels usos notarials itàlics a Catalunya, "Lligall", 7 (1993), pp. 32 i 34 . També és aquest el còmput aplicat, per exemple, en l'edició del primer volum notarial de Terrassa (Pere PUIG I USTRELL, Capbreu primer de Bertran acolit, notari de Terrassa, 1237-1242. Barcelona, 1992); encara que no es diu de forma explícita sinó que es parla del "còmput usat fins 1351", tal com es po comprovar en la transcripció, per exemple en els documents 622-623, el còmput aplicat és el florentí. El problema que suposa el còmput o el doble còmput de l'Encarnació ens resulta poc clar, i també poc familiar pel fet que aquest còmput no és utilitzat en l'Escrivania vigatana.

${ }^{9} \mathrm{Cf}$. M. Crusafont I Sabater-M. Garcia Garrido-Anna M. Balaguer, Història de la Moneda Catalana, Barcelona, 1986. Veure també Thomas N. BISSON, Coinages of Barcelona (c. 1209-1222). The documentary evidence, "Studies in Numismatic Method Presented to Philip Grierson", Cambridge, 1983, pp. 193-204 (inclòs tambe en el recull Thomas N. BISSON, Medieval France and her Pyrenean Neighbours. Studies in early institutional History, Londres, 1988, pp. 339-349).

${ }^{10}$ De fet són diversos els casos en què en dos documents relacionats amb un mateix afer, en un cas es parla símplement de "solidos" i en l'altre s'explicita que es tracta de sous barcelonesos de doblenc. És el cas, per exemple, dels mutus esponsalicis dels documents 46 i 47, 105 i 106, 265 i 266,319 i 320,338 i 339,545 i 546,1160 i 1161 , etcètera. També queda documentada la identitat en altres documents relacionats que fan referència a la mateixa quantitat esmentant i no esmentant respectivament la unitat: 715 i 716 (debitori i donació de debitori), 1093 i 1094 
La moneda de doblenc s'utiliza en totes les tipologies si bé ja hem vist que en algunes el seu predomini és sensiblement menor. El seu percentatge d'ús puja fins al 97,4 o 97,3 en les vendes de terres o en els preus dels establiments, mentre que baixa a un $66 \%$ en les àpoques, al $51,7 \%$ en els documents relacionats amb societats i comandes i fins al $36 \%$ en els censos dels establiments. Es tracta d'una moneda encunyada per la corona, de poca qualitat i avalada per un poder polític de segon ordre a nivell internacional cosa que fa que sigui apta sols per a l'ús local -establiments, compres,...-, en el qual esdevé gairebé exclusiva mentre que en tipologies $\mathrm{i}$ àmbits més relacionats amb activitat mercantil i comercial cedeix lloc de manera notable a numeraris de major valor i prestigi, acceptats de forma virtualment universal i per tant aptes per a transaccions de major abast.

L'espectre de valors expresats en moneda barcelonesa de doblenc, encara que sigui sols a tall de curiositat, va des dels 3 diners fixats com a part del cens que s'estableix en un arbitratge, fins als 13.500 sous de preu d'una liquidació de comptes" ${ }^{11}$ La proporció entre els valors extrems -1:54.000 - significa la variabilitat més alta de les que trobem en els diferents numeraris.

\subsection{Moneda melgoresa}

La moneda melgoresa o de Melguelh (o Melgueil), documentada en 162 dels documents del volum, esdevé la segona moneda més corrent en aquesta documentació notarial d'ACF-1, encara que a gran distància de la primera, la barcelonesa de doblenc.

La moneda melgoresa és una moneda de quatern, encunyada a Megalona. Les primeres emissions correspongueren als comtes de Melguelh, i després passaren al domini dels bisbes de Megalona-Montpeller quan el comtat passà a domini episcopal arran de la croada albigesa. Com que el rei Jaume I com a senyor de Montpeller tenia dret de senyoratge sobre aquesta moneda pròpia de la ciutat, era admesa i circulava lliurement tant pel Principat com pels altres dominis de la corona, i la seva bona qualitat en un

(venda i compromís d'anul-lació de venda), 1632 i 1633 i 1634 (definició de drets, venda de terra i compromís d'anul·lació),...Els números de document a què ens referim es corresponen amb l'ordre correlatiu en què estan al volum i a la transcripció que vam aportar com apèndix a la Memòria de Llicenciatura (U.B., 1994).

"2453, 2534. 
marc en què la moneda oficial havia baixat de llei van fer que esdevingués una moneda molt acceptada com a moneda intercomtal ${ }^{12}$.

Encara que cau fora del nostre marc cronològic i que tractarem més avall les equivalències que aporta el volum, el valor de la moneda melgoresa és establert en la Taula de Canvi que creà Jaume I a València el 1247 en lleugerament superior a la moneda barcelonesa, que era encara la de doblenc. Concretament s'estableix que 16 diners melgoresos valen 12 diners reals de València, mentre que 18 diners barcelonesos valen també 12 diners valencians ${ }^{13}$. És a dir, un diner melgorès valia, a València i el 1247, 1,125 diners barcelonesos, o el que és el mateix, 8 diners melgoresos valien 9 diners barcelonesos. A Vic i a la quarta dècada del XIII la diferència de valor, com veurem més avall, era més significativa, a favor, és clar, de la melgoresa.

Els documents parlen símplement de "solidos malguirienses" o de "libras malguirienses" o "libras denariorum malguriensium". L'adjectiu sol estar abreujat - "malg", "malgrn" normalment—, i en els casos en què el mot és suficientment desenvolupat si bé sembla predominar la forma "malguiriensis"14 aquesta alterna amb "malguriensis"15.

La moneda melgoresa representa el 6,9\% de les referències a moneda, però de nou la freqüència no és uniforme en les diferents tipologies sinó que, per exemple, arriba a representar el $25,9 \%$ de les referències a moneda en les societats i comandes o el $14 \%$ en els debitoris, mentre que baixa a un $3,9 \%$ de les referències a moneda en les àpoques o un 0,4 en les vendes de terres (una sola venda), i és inexistent en alguna tipologia notable com els establiments, on no surt ni en els preus ni en els censos.

El que marca la proporció general de la moneda melgoresa és el seu pes important dins la major de les tipologies, els debitoris, ja que com hem dit són 103 els documents en què l'objecte del deute és exclusivament

\footnotetext{
${ }^{12}$ A falta d'altres notícies en la bibliografia consultada, ens hem basat en la veu "melgorès" del "Diccionari d'Història de Catalunya" (Barcelona, Edicions 62, 1992) signada per Anna Maria Balaguer.

${ }^{13}$ BOTET I SISÓ, Les monedes, p. 47.

${ }^{14} 224,349,529,816,904$, per exemple, pel que fa als 1000 primers documents.

${ }^{15} 49,225$, per exemple, pels primers 100 documents del volum.
} 
moneda melgoresa ${ }^{i 6}$, cosa que implica que un $63,6 \%$ dels documents en melgoresa són debitoris ${ }^{17}$.

Com queda clar en analitzar els debitoris, alguns d'aquests documents amb melgoresa estan explícitament relacionats amb afers ultra-pirinencs $\mathrm{i}$ altres amb diferents indrets dels territoris catalans, inclosa Mallorca, però, com d'altra banda és lògic, no hi trobem casos en què es reflecteixi una relació amb territoris aliens a la sobirania comtal catalana. Alhora, però, és emprada també en debitoris relacionats amb un àmbit en principi estrictament local, com són els debitoris de legítima, aixovar o dot.

De fet, d'acord amb la doble condició de la moneda melgoresa que per una banda és moneda forana de bona qualitat i per l'altra és admesa oficialment i lliurement als comtats catalans per tal com al capdevall és moneda pròpia d'un dels dominis de senyoria de Jaume I, la moneda melgoresa sembla jugar un paper a mig camí entre la moneda estrictament local i la moneda estrictament forana, de manera que les seves recurrències estan més sovint relacionades amb afers d'abast estrictament local que no pas la moneda mussulmana però menys que la moneda local de doblenc, mentre que estan relacionades amb afers d'abast extra-local o internacional en major proporció que la moneda autòctona de doblenc però en menor proporció que les monedes mussulmanes, sobretot que els besants. Per dir-ho d'altra manera, funcionalment, la moneda melgoresa se situaria entre la moneda mussulmana, especialment els besants ${ }^{18}$, com a moneda molt concentrada en tipologies documentals vinculades amb negocis comercials i mercantils internacionals, per una banda, i la moneda de doblenc, que dins la polivalència té un clar predomini en els negocis o afers locals (vendes de terres, establiments, pactes matrimonials etc). La moneda melgoresa semblaria situar-se entre els dos extrems encara que amb bastant pes en l'àmbit

\footnotetext{
${ }^{16}$ Insistim que hem contemplat aquí sols els debitoris en què l'objecte és exclusivament moneda. Si contemplessim també els que són fets part en moneda i part en espècie els debitoris amb moneda melgoresa són dos més, 105, cosa que no fa sinó incrementar la proporció en el sentit que fem notar.

${ }^{17}$ Els debitoris, tot i ser la tipologia més important del volum agrupa 815 , és a dir el $24,6 \%$ dels 3308 documents del volum, i en canvi agrupa el $63,6 \%$ dels documents amb moneda melgoresa.

${ }^{18} \mathrm{~T}$ ot $\mathrm{i}$ que el besant és una moneda originàriament bizantina, com el seu nom indica, els que tenim documentats a Vic a la quarta dècada del XIII creiem, com tractarem més endavant, que no són els besants bizantins sinó els besants mussulmans d'argent encunyats a imitació d'aquells.
} 
mercantil-comercial, que per lògica en aquest cas es dirigiria vers l'ambit nord-pirinenc en comptes del mediterrani.

El valor més alt expresat en moneda melgoresa és de 6.000 sous en un rebut en societat vinculat amb un viatge a França. El més baix, 9 sous en un debitori pagador a Mallorca ${ }^{19}$. La relació entre els dos valors extrems, $1: 666,6$. Ni els valors ni la relació no són tan extrems com en el cas de la moneda de doblenc.

\subsection{Morabatins}

En 91 documents del volum són esmentats morabatins, anomenats simplement "morabatinos", "morabatinos in auro", "morabatinos auri fini rectique ponderis", "morabatinos in auro fino", "morabatinos auri fini anfusinos"20, "morabatinos aupinos (sic) auri fini rectique ponderis" $^{21} \mathrm{o}$ també simplement "aureos"22. En un sol cas i cap al final del volum es parla de "morabatinos novos in auro", estant l'adjectiu afegit en interliniat $^{23}$.

Segons Botet es tracta de moneda d'or castellana, que seria feta a imitació dels antics morabatins almoràvits. A principis del segle valdria 7 sous de quatern, el 1243 valdria uns 10 sous de doblenc, el 1246 a València valdria igual que 9 sous barcelonesos de doblenc, i el 1254 valdria 14 sous també de doblenc ${ }^{24}$. Que la moneda que ens apareix a ACF-1 és la castellana ho sembla confirmar la referència a "morabatinos auri fini anfusinos" que hem esmentat i que faria referència a Alfons VIII de Castella (1158-1214). La singular o anòmala referència esmentada a morabatins nous suposem que cal entendre-la en contraposició als morabatins originals almoràvits. L'equivalència que tenim al volum, com veurem més avall, és de 11 sous de doblenc.

\footnotetext{
${ }^{19} 2536,2682$.

${ }^{20} 374$.

${ }^{21} 923$.

${ }^{22}$ Aquesta és la denominació en l'àpoca del document 637. En establir la quantitat rebuda és parla de "DCC aureos", i llavors s'estableix "ita scilicet quod racione predictorum morabatinorum [l", cosa que no deixa lloc a dubte. Igualment queda documentada l'estricta equivalència de la denominació en els documents $2838,3255,3256$.

233240.

${ }^{24}$ BOTET I SISÓ, Les monedes, II, pp. 34, 61, 47 i 61, respectivament.
} 
Els 91 documents amb referència a morabatins signifiquen un 3,9\% de les referències a moneda. Malgrat el baix percentatge és la tercera moneda i és present a la majoria de tipologies. De les sis tipologies que hem agafat com a significatives o utilitzables per les dimensions i les referències a moneda, només en la de societats $\mathrm{i}$ comandes no hi ha cap referència a morabatins, absència que resulta significativa. En els altres casos, en les àpoques signifiquen un $14,6 \%$, en els censos dels establiments un $9,8 \%$, en les vendes de terres $i$ en els preus d'establiment un $1,8 \%$ i en els debitoris signifiquen un $0,9 \%$. No ens cansarem de fer notar que en aquests casos de percentatges tan petits en tipologies no excessivament voluminoses estem parlant de nombres de referències molt baixos - $15,4,4,2$ i 7-, cosa que treu significativitat rigurosa als valors ja que qualsevol variació circumstancial d'una sola referència fa variar significativament el percentatge, tot i que, per altra banda, són els resultats que dóna la base de 3.308 documents del volum que sí que cal considerar suficientment significativa pel periode de tres anys i tres mesos que tractem.

Com es veu, aquestes sis tipologies que hem triat com a significatives recullen 32 de les 91 referències a morabatins. La resta està repartida en altres tipologies. Així, consten morabatins en 5 donacions-dot, 13 esponsalicis, 8 compromisos, 3 liquidacions, 3 vendes de censos,... L'absència en les societats i comandes reflectiria la poca relació comercial amb els àmbits propis d'aquesta moneda, com confirma el fet que no hi ha absolutament cap referència a relacions amb Castella.

Els valors que surten consignats en aquesta moneda, encara que sigui només com a curiositat, van de 800 morabatins en una reparació d'injúries a 1 morabatí com a cens anual en diversos documents ${ }^{25}$. La relació, no cal dir, 1:800.

\subsection{Moneda de quatern}

La quarta moneda en ordre decreixent d'aparicions és la moneda de quatern, utilitzada en 72 documents.

La moneda de quatern és la que encunya el poder reial a Catalunya a la primera part del segle XIII fins la substitució per la moneda de doblenc de la qual ja hem parlat. El segle XIII comença, en continuitat amb el segle

\footnotetext{
${ }^{25} 1596$, i $640,890,1023, \ldots$
} 
anterior, amb una moneda de quatern, de quatre parts de plata sobre dotze, és a dir quatre de plata i vuit de lliga, cosa que implica un percentatge del $33,3 \%$. El quatern que circula a principis de segle és moneda emesa per Alfons I; es tracta de moneda batuda a talla de 54 sous per marc de plata (un marc de plata són 234,2734 grams $^{26}$ ), amb una talla oficial de 44 sous per marc. Posteriorment, el 1209, les dificultats de la hisenda comtal porten a Pere I a batre una moneda fraudulenta, que de fet és de coure emblanquit amb un bany de plata, cosa que dóna una moneda pràcticament sense valor intrínsec. Inicialment la talla oficial fou de 55 sous el marc, però aviat quedà devaluada per la mala qualitat. Més tard, després de la victòria de las Navas de Tolosa que restablí en part el flux d'or des de les terres islàmiques a través de les pàries, el rei fa un intent per a millorar la qualitat de la moneda i torna a batre quatern de bona llei, que superarà fins i tot en qualitat les encunyacions del seu pare Alfons I, per bé que la mala qualitat de les encunyacions anteriors fa que sigui acceptada amb malfiança i se li establei$\mathrm{xi}$, a nivell de mercat, una talla de 64 sous per marc ${ }^{27}$. Pel que fa a les encunyacions dels primers anys de Jaume I ja n'hem parlat en l'apartat de la moneda de doblenc.

Tanmateix, parlar de quatern a Vic al segle XIII té una dificultat afegida. Vic té una peculiaritat prou significativa i important pel tema que estem tractant, i és que el seu bisbe conserva encara la facultat d'encunyar moneda, facultat que es remonta als primers temps de la restauració del bisbat, a les darreries del segle $\mathrm{IX}^{28}$. La moneda episcopal vigatana s'havia restablert el 1174 sota el bisbe Pere de Redorta, qui en aquest any bat moneda a llei de quatre diners d'argent, és a dir, moneda de quatern. Es bat amb talla de 18 sous per marc de metall, que equival a 54 sous el marc de plata $^{29}$.

\footnotetext{
${ }^{26}$ Botet I Sisó, Les Monedes, vol. II, p. 39.

${ }^{27}$ Miquel Crusafont I SABATER, Numismàtica de la Corona Catalano-Aragonesa, pp. 72 75. Crusafont-Garcia Garrido-Balaguer, Història de la Moneda Catalana, p. 62.

${ }^{28} \mathrm{Cf}$. Josep Maria Passola I PALmada, La moneda medieval de Vic $i$ els origens de la banca. El primer banc públic d'Europa, "AUSA", XV (1993), p. 195.

${ }^{29}$ PASSOLA, op. cit., p. 195. Eduard JUNYENT I SUBIRÀ, Jurisdiccions i privilegis de la Ciutat de Vich, Vic, 1969, p. 30. Passola considera aquesta talla de 54 sous per marc de plata com una talla diferent de la de la ceca barcelonina, que era de 44 sous per marc. Crusafont, però (Numismàtica., p. 33) creu que aquesta moneda barcelonina de talla oficial de 44 sous tenia de fet una talla real de ceca de 54 sous, i que els 10 sous de diferència és la part que ha de cobrir les despeses d'encunyació i el benefici del rei. Sent així que els 54 sous per marc de la moneda vigatana restablerta cal entendre'ls com talla de ceca, això significaria que la moneda
} 
Desprès d'aquesta emissió, no en tenim cap altra de documentada fins els voltants de $1254^{30}$. El 6 de març de 1254, el bisbe Bernat de Mur restableix l'encunyació de moneda, obligant als habitants de Vic a emprar-la. El maig del 1254 el capítol i el bisbe Bernat de Mur es queixen al Veguer de Vic pel fet que aquest, per manament del rei, ha fet cessar la fabricació de moneda Episcopal. Arran d'aquest conflicte el bisbe hauria acudit a Roma, al papa Innocenci IV, i n'hauria obtingut una butlla del 15 de juliol del mateix any confirmant i aprovant l'encunyació de moneda episcopal ${ }^{31}$. Dos anys després, el 17 d'octubre de 1256 Bernat de Mur fa una nova restauració de la moneda episcopal, fixant la llei d'aquest numerari a 4 diners de plata pura, i talla de vint sous per marc, insistint en l'obligatorietat exclusiva del seu ús ${ }^{32}$.

Acabem de dir que no hi ha cap emissió vigatana documentada fins els voltants de 1254 . La primera referència explícita a aquesta encunyació era fins ara l'esmentat document del 6 de març de 1254, però un document

vigatana era de la mateixa llei i mateixa talla que la barcelonina.

${ }^{30} \mathrm{Cf}$. Rafel GineBra i Molins, La pretesa moneda de tern de Vic de 1244, "AUSA", XVI (1994-95), pp. 185-194.

${ }^{31} \mathrm{Cf}$. JUNYENT, Jurisdiccions, pp. 144-145, privilegis 101-103. Josep GuDIOL, Las monedas episcopals vigatanas. Estudi de las encunyacions que s'han fet en Vich desde'l sigle X al XIV, Vic, 1896, p. 24. Juan Luís de MONCADA, Episcoplogio de Vich, II, p. 30. Creiem una duplicació del mateix fet els privilegis 101 i 104 de l'obra de Junyent. Ambdós són del 6 de març, un del 1254 i altre del 1255, però tots dos remeten al mateix document, ACV, c.6, 2013, que és de 1254. A CRUSAFONT, Numismàtica, p. 34 hi ha, com a error d'impremta, una petita trasposició de xifres. Diu concretament que "El març de 1245 el bisbe Bernat de Mur restaura la moneda episcopal de Vic. Dos mesos més tard Jaume I ordena als moneders que suspenguin l'emissió. El juliol del mateix any el bisbe obté una confirmació del seu dret de moneda del papa Innocenci IV". Tot això, però, no passa el 1245 sinó el 1254.

${ }^{32}$ JunYent, Jurisdiccions, p. 145, priv. 106. Segons Passola, l'actuació del Bernat de Mur sobre la moneda episcopal vigatana en aquests anys 1254-1256 hauria estat un dels motius que hauria portat a Jaume I a millorar la qualitat de la seva pròpia moneda substituint la de doblenc per la de tern: el bisbe, cansat de la escassa qualitat de la moneda reial circulant hauria prohibit la seva circulació a la ciutat de Vic, fent obligatoria la moneda episcopal de quatern, que si bé tenia un pes lleugerament inferior a la de doblenc contenia el doble de plata que aquella. Això hauria significat com un desafiament al rei, que s'hauria vist posat en evidència, i s'hauria sentit obligat a actuar sobre la qualitat de la seva pròpia moneda (PASSOLA, La moneda medieval de Vic, p. 197.) La hipòtesi és interessant, però cal matisar la trascendència d'aquest fet sobre l'encunyació de tern de Jaume I recordant que la intenció de millorar la moneda aquest la té ja abans d'aquesta encunyació de quatern del bisbe de Vic. No en va el rei ha encunyat ja tern a Aragó des de 1236, i a València des de 1246. A Catalunya diversos factors l'obliguen a retardar aquesta encunyació, sobretot compromisos adquirits i el jurament que havia fet en imposar la moneda de doblenc de no tornar a modificar més la moneda. 
inèdit $^{33}$ ens permet aportar noves $\mathrm{i}$ inèdites dades relatives a aquesta encunyació, dades que no deixen de ser una precisió més al panorama monetari vigatà de la primera meitat del segle XIII.

Hem dit que el 6 de març de 1254 Bernat de Mur restableix l'encunyació de la moneda episcopal vigatana, i el maig del mateix any junt amb el Capítol es queixa al Veguer que ha fet aturar l'encunyació per manament del rei. Doncs bé, aquestes dates no representen ni l'inici de l'encunyació, ni tampoc l'inici del conflicte amb el poder reial. Segons consta en una anotació del cinquè volum de la sèrie que encapçala el volum que hem emprat pel nostre estudi, el 22 de desembre de 1253 els moneders que estaven encunyant la moneda del bisbe de Vic van rebre carta del Rei manant-los aturar la seva activitat. La carta és datada a Perpinyà el 12 de desembre. Si el manament va tardar deu dies a ser notificat a Vic als moneders cal suposar que la noticia de l'encunyació tardà, com a mínim, un temps semblant a ser coneguda pel rei a Perpinyà i per tant cal pensar que almenys des de principis de desembre de 1253 s'està encunyant moneda episcopal. Vegem el text íntegre d'aquesta anotació inèdita:

\footnotetext{
XI kalendas ianurarii.

Notum sit cunctis quod dominus Jacobus, Dei gracia Rex Aragonum, Mayoricarum et Valentie, Comes Barchinone et Urgelli et dominus Montispesulani misit literas ${ }^{34}$ Anno Domini MCCL tercio, XI kalendas januarii operariis et monetariis qui operabantur et cudebant monetam Episcopi Vicensis in villa Vici sub hac forma: "Jacobus, Dei Gracia Rex Aragonum, Maioricarum et Valencie, comes Barchinone et Urgelli et dominus Montispesulani fidelibus suis operariis et monetariis operantibus in moneta episcopi Vicensis Salutem et Graciam. Mandamus vobis sub pena personarum et omnium bonorum vestrorum quatinus non operemini nec aliquod opus faciatis in aliqua moneta pro Episcopo Vicense nec per aliqua alia persona. Datum Perpiniani II idus decembris". Que quidem forma ad rei memoriam presentibus testibus inferius nominatis ${ }^{35}$ scripta fuit in formam publicam ${ }^{36}$ et redacta (ACF-5, 112-1).
}

\footnotetext{
${ }^{33} \mathrm{El}$ document, efectivament inèdit, és esmentat a Joseph GUDIOL Y CUNILL, Les bregues sobre lo senyoriu de Vich en temps del Rey Jaume I, Barcelona, 1909, p. 9.

${ }^{34}$ Segueix qui ratllat.

${ }^{35}$ Segueix fuit ratllat.

${ }^{36}$ Segueix annotata ratllat.
} 
No és un document notarial sinó una anotació feta, de forma inusitada, "ad rei memoriam", cosa que reflectiria que per l'escrivà constituia un fet anòmal, seriós o fins i tot greu.

Amb probabilitat el rei va ser informat amb promptitut pels seus representants a Vic de què el Bisbe de Vic estava batent moneda i per tant és poc probable que aquesta encunyació s'iniciés gaire abans de principis de desembre. Quan, però, entrà en circulació aquesta moneda episcopal vigatana? El mateix volum notarial ens en forneix la informació. No hi ha cap referència a aquesta moneda en els darrers mesos de 1253 , en què el panorama monetari no sembla molt diferent que el de vint anys enrere - predomini absolut de la moneda barcelonesa de doblenc i referències esporàdiques a moneda de quatern, encara, relacionada amb censos, i a morabatins, masmudines, besants,...-; no hi ha ni tan sols cap referència a aquesta moneda vigatana des de principis de desembre fins a final d'any, malgrat que com hem vist és evident que ja s'estava encunyant. Recordem que estem en còmput de la Nativitat i que s'inicia l'any per Nadal. El 1253 Nadal cau en dijous, i al volum notarial no hi ha anotacions fins el dilluns següent, dia 29 , en què s'encapçala la pàgina amb un solemne ANNO DOMINI $\mathrm{M}^{\circ} \mathrm{CC}^{\circ} \mathrm{L}^{\circ}$ QUARTO i IIII kalendas januarii. El quart document de l'any de la Nativitat de 1254 és el primer en què apareix la moneda episcopal vigatana: Ferrer de Cuspineda, sacerdot, frare i rector de l'Hospital d'Arnau de Cloquer ven a Ferrer de Plans una peciola de terra que Berenguer Gayol va donar al dit hospital, al Coll de Vic, ..."pro XIII solidis et VI denariis monete curribilis vicensis de quaterno" (ACF-5, 113-4), és a dir, moneda circulant o corrent vigatana de quatern, encara que el mot curribilis és gairebé reivindicatiu per tal com la moneda és clarament moneda circulant des de fa sols uns dies. La segona referència és dos dies més tard, el 31 de desembre, set documents més tard, al document 114-3 en què Pere de Sant Joan, de Taradell, ven a Guillem de Real, sabater, i a qụi vulgui, "pro XVI solidis monete vicensis de quaterno" els esplets d'una peça de terra, durant vuit anys. La tercera, al document següent, 114-4, del mateix dia 31 , en què Pere de Gualba i Peyró, canonges de Vic, fan reducció del cens d'un honor a Berenguer de Vilaseina, al cens de mitja quartera de forment a mesura de Vic, "et sex denarios monete vicensis de quaterno". A partir d'aquí les referències es van incrementant, alternant-se però amb els altres numeraris sobretot lògicament amb el doblenc ja que el quatern episcopal en tot cas serà només obligatori en els tractes i compres dins la ciutat de Vic. 
Així doncs, no queda clar si el bisbe inicià la seva encunyació fent prèviament un restabliment oficial de la moneda episcopal com el de març de 1254 , però sembla que l'encunyació s'hauria iniciat a principis de desembre de 1253 a la pròpia ciutat de Vic, i pot ser que s'encunyés durant el mes de desembre amb la intenció de posar el nou numerari en circulació just en iniciar l'any de la Nativitat de 1254 . És efectivament, com hem vist, en les primeres anotacions d'aquest any de la Nativitat, el dia 29 de desembre de 1253 - còmput modern - on hi ha la primera referència a la moneda de quatern episcopal vigatana com a moneda en circulació, i probablement no és casual que sigui en un document atorgat per un eclesiàstic vigatà. També és atorgat per canonges vigatans el tercer document, dos dies més tard, i en aquest cas també cal considerar gairebé un acte reivindicatiu i bel-ligerant l'utilitzar aquesta moneda nova, basada en prerrogatives jurisdiccionals seculars del bisbe de Vic i desautoritzada pel rei Jaume des de Perpinyà, i més l'utilitzar-la per a un àmbit tan tradicionalment immovilista, continuïsta i inercial com són els censos.

Les encunyacions episcopals vigatanes, malgrat que s'extingirien al $\mathrm{XIII}^{37}$ arriben almenys fins al darrer quart del segle ${ }^{38}$.

Així, finalment i tornant a la nostra documentació, quina és la moneda de quatern que surt en 72 documents d'ACF-1? És moneda episcopal vigatana o és la moneda barcelonesa? La polèmica és fictícia, però la bibliografia ens obliga a aturar-nos-hi.

Alguna bibliografia, tot i no tenir cap encunyació vigatana documentada entre 1174 i 1254 - ara 1253 -, ha donat continuïtat a les encunyacions de quatern episcopal entre ambdues dates. Passola, dóna per segura l'obligatorietat de la moneda episcopal a Vic el 1222, i per consegüent, la seva existència ${ }^{39}$. Tanmateix ho fa necessàriament extrapolant dades de documents posteriors com el de març de $1254 \mathrm{i}$ el d'octubre de 1256 que hem esmentat més amunt. Altres autors, a partir d'un petit lapsus de lectura han donat existència durant prop d'un segle a una anòmala moneda vigatana de

\footnotetext{
${ }^{37} \mathrm{Cf}$. Miquel Crusafont I SABATER, La moneda catalana local (s. XIII-XVIII), Barcelona, 1990, p. 316.

${ }^{38}$ Crusafont I Sabater, Numismàtica, p. 34.

${ }^{39} \mathrm{Cf}$. PASSOLA, La moneda medieval de Vic, p. 196. Aquesta presència d'una moneda particular a Vic significaria, segons Passola, una motivació més per a instalar taula de canvi reial a Vic per introduir-hi la moneda de doblenc, i malgrat que a la ciutat seria obligatòria la moneda episcopal de quatern, la necessitat de fer pagaments fora ciutat, on era obligatòria la reial de doblenc, degué afavorir la introducció d'aquest numerari.
} 
tern que s'hauria encunyat el 1244 i que no va existir mai ${ }^{40}$. El cert, però, és que el 1254 es parla de restabliment de l'encunyació, i el més cert encara és que ni els pergamins vigatans de finals del XII i de la primera meitat del XIII ni la riquíssima i continua sèrie notarial que s'inicia amb el volum que estudiem no parlen de cap moneda vigatana fins les encunyacions de quatern del bisbe Bernat de Mur que com hem vist s'inicien no amb el document de 6 de març del 1254 sinó probablement el desembre de 1253 i en canvi en els anys que segueixen a aquestes encunyacions és ben patent la distinció entre moneda barcelonesa i moneda vigatana. Ens cal concloure, per tant, que en la quarta i quinta dècades del segle XIII, i molt probablement en tota la primera meitat del segle, no existeix, com a moneda circulant, la moneda episcopal vigatana, ni de quatern ni de cap tipus.

El quatern que tenim documentat a ACF-1 és quatern de Barcelona, tant pel fet que no n'hi ha d'altre - a part de la moneda melgoresa que queda inqüestionablement diferenciada - com pel fet que així consta en els ben escassos documents en què s'esmenta la filiació o procedència de la moneda.

La moneda de quatern surt esmentada a ACF-1 com "bone monete de quaterno" o "monete de quaterno", i de manera menys freqüent "monete quaternale" o "monete de quaternalis" 41 . En tres documents consta explícitament que es tracta de moneda barcelonesa: "monete barchinonensis de quaterno o "denarios barchinonenses monete de quaterno"42. És també evidentment quatern els casos en què es parla senzillament de "bone monete"; l'expressió s'ha de considerar comparativa respecte a la moneda de doblenc i com hem dit a banda dels casos que es troba aïllada surt en la fòrmula "bone monete de quaterno" en 33 dels 72 documents amb moneda de quatern ${ }^{43}$, i en un altre cas resulta explícita la oposició bona monedamoneda de doblenc ${ }^{44}$ mentre que la mateixa expressió només es dóna, pel

\footnotetext{
${ }^{40} \mathrm{Cf}$. GineBRA I Molins, La pretesa moneda de tern.

${ }^{41} 2534,3058$.

${ }^{42} 2490$ i 2586 , i 1797 .

${ }^{43} 1,2,245,312,511,522,665,707,1063,1116,1270,1318,1505,1572,1598,1701$, $1724,1762,1835,1893,1901,2310,2328,2455,2633,2658,2785,2807,2835,3060,3074$, $3157,3303$.

${ }^{44 " . . . ~ e t ~ f a c i a s ~ I I I ~ b o n e ~ m o n e t e ~ v e l ~ V I ~ d e ~ d u p l o, . . . ~ e t ~ f a c i a s ~ i n d e ~ X I I ~ d e n a r i o s ~ b o n e ~ m o n e t e ~}$ vel II solidos de duplo" (2757).
} 
que fa als altres numeraris, en 2 dels 1945 documents amb moneda de doblenc ${ }^{45}$ fet que permet considerar-ho un error.

El quatern barceloní no deixa de ser una moneda anacrònica des de l'encunyació i imposició de la moneda de doblenc a partir de 1222 , i és en aquest sentit que la trobem de manera especial en les tipologies més propenses a les inèrcies i anacronismes. És en aquest sentit que si bé en el conjunt del volum suposa un $3,1 \%$ de les referències a moneda és absolutament absent en les grans tipologies com són els debitoris, o en els preus de vendes de terres; apareix un sol cop en societats i comandes i encara en una forma significativament diferent a l'habitual ja que es tracta d'un rebut en què a banda de sis mil sous melgoresos i 52 marcs d'argent es parla de 20 marcs "monete quaternale"; per la denominació i també pel tipus de document sembla que es considera la moneda simplement pel pes en plata més que pel valor nominal ${ }^{46}$. Per contra, ja ho hem comentat abans, en el $39 \%$ dels censos que es fixen en els establiments s'utilitza precisament aquesta moneda, $\mathrm{i}$ en les àpoques té un valor lleument més elevat que el general del volum, un $3,9 \%$. Pel que fa a d'altres tipologies, en les lloacions, tipologia en què incloem les lluïcions i que per tant és també una de les propenses a perpetuar o prolongar esquemes anacrònics, la moneda de quatern apareix en 11 dels 66 documents en què hi ha referència a moneda, un $16,6 \%$.

Les majors quantitats documentades serien els 650 sous de quatern que surten en un arbitratge com a quantitat que ha de prestar una de les parts, o els 20 marcs de moneda quaternal, que tenint en compte que la talla de la moneda de quatern barcelonina és de 44 sous per marc serien 880 sous $^{47}$. Les menors quantitats serien els censos d'un diner de quatern que s'estableixen en algun document ${ }^{48}$. La proporció entre els valors extrems és de les més altes, $1: 10.560$.

Molts dels documents amb moneda de quatern són documents relacionats amb tractes o negocis previs, cosa que pot explicar l'ús d'aquest

\footnotetext{
${ }^{45} 213$ i 278.

${ }^{46} \mathrm{Per}$ altra banda, també era moneda quaternal la melgoresa, però el fet que aquests vint marcs es comptabilitzin a part dels sis mil sous melgoresos permet pensar que es pugui tractar de quatern barceloní.

${ }^{47} 3058,2536$.

${ }^{48} 1725,2178$
} 
numerari anacrònic. Així, hi tenim cessions de lloc en deutes previs ${ }^{49}$, definicions de censos, de demandes o de deutes ${ }^{50}$, liquidacions de comptes $^{51}, \ldots$ Afers tots ells que poden tenir el seu origen en un periode on la moneda de quatern era menys anacrònica.

Tipologies relacionades amb negocis previs i tipologies que per naturalesa són propenses al continuïsme són per tant, i de manera lògica, els àmbits principals en què trobem l'oficialment anacrònica moneda de quatern, moneda que ha passat a ser minoritària però encara no inhabitual sinó que deu anys després de la seva substitució teòrica és el quart dels nou numeraris que tenim documentats a Vic, tot i representar sols poc més d'un $3 \%$ de les referències a moneda, $i$ sense un descens significatiu en el periode que cobreix el volum tal i com hem vist en els talls successius que hem establert al principi de l'article.

\subsection{Besants}

Seguint en l'ordre de freqüència decreixent, la cinquena moneda és el besant, que surt en 67 dels 3.308 documents del volum. Aquesta és la moneda que té una distribució més anòmala al llarg del volum ja que com hem vist en les xifres i gràfics inicials més de la meitat de les referències a besants són als primers 1000 documents del volum en què constitueix la tercera moneda després del doblenc i la melgoresa, superant morabatins $\mathrm{i}$ quatern. Caldria un marc cronològic més ampli per veure si es tracta d'un fet puntual o si la tendència persisteix i es confirma.

Sobre el besant que corre per la Catalunya del primer terç del XIII poca cosa en podem dir. Poca informació n'hem trobat a la bibliografia. Les 67 referències ens parlen de "bisancios", "bisancios de milareses"52, "bisancia de terra Miralmumini", "bisancios argenti", "bisancios argenti fini bonos et veteres", "bisancios veteres argenti fini rectique ponderis", "bisancios veteres et bonos de terra Miramamulini", "bisanciis boni argenti de terra Miramamulini" "bisancios argenti boni" i altres variants,... Tractant-

\footnotetext{
${ }^{49} 395,844,1387,2509$.

${ }^{50} 522,668,1318,2461$.

$51312,1221$.

${ }^{52}$ Ens remetem també a l'apartat sobre millaresos, amb els comentaris i dubtes que hi hem plantejat.
} 
se de referències contemporànies i sense denominació clarament distintiva entenem que cal creure que en tots els casos es tractaria de la mateixa moneda; es tractaria, per tant, de besants d'argent mussulmans ("Miraumunins" essent una degradació de "Emir al Muminin"), els besants de plata que cita Botet i Sisó el 1208. Segons Botet, "besant" es referia tant a la moneda bizantina com, especialment, a la moneda àrab encunyada a imitació d'aquella, més coneguda i de curs més freqüent que la bizantina; les referències esmentades creiem que estarien relacionades amb un mateix tipus de besant, que seria, evidentment, el mussulmà. Segons Botet aquesta moneda acabaria sent anomenada "millarès"53, equivalència o identitat que en qualsevol cas no és vigent a Vic al periode que estudiem on els millaresos surten en una ocasió com a unitat de forma aillada però en altres casos surten clarament com a divisors del besant: "XXVII bisancios de milareses"54, "V bisancios argenti de milarisis"55, o, més clarament, "XL bisancios et $\mathrm{V}$ millarisios argenti bonos veteres de terra Miraumunins", "VII bisancios et IIII' milariis" i "XVI bisancios argenti et II milerees"s6.

Junt amb l'anòmala distribució al llarg del volum, un altre tret característic dels besants és la seva especialització, derivada de la seva condició de moneda estrictament estrangera i d'origen mussulmà. S'ha de considerar la moneda més específicament vinculada a afers i negocis relacionats amb comerç mediterrani. Així, tot i que suposa un $2,8 \%$ de les monedes del volum, és inexistent en els establiments tant pel que fa a preus com pel que fa a censos, és també inexistent en una altra de les tipologies de gran pes com són els pactes matrimonials ${ }^{57}$, i surt en un únic cas en el preu de venda de terra ${ }^{58}$, i en canvi representa un $3,3 \%$ de les referències a moneda en els debitoris, puja fins un $8,7 \%$ en les àpoques, i, més significativament encara, representa un $17,2 \%$ de les referències a moneda

\footnotetext{
${ }^{53}$ BotET I SISÓ, Les monedes, II, p. 57.

${ }^{54} \mathrm{En}$ dos documents relacionats amb el mateix afer $(67,774)$.

${ }^{55} 1453$.

56394, 2198, 2622.

${ }^{57}$ Als pactes matrimonials $\mathrm{i}$ acordant amb el panorama que es va dibuixant, les quantitats s'estableixen normalment en moneda de doblenc en segon lloc s'utilitza la moneda melgoresa, $i$ en tercer lloc els morabatins, i un sol cop la moneda de quatern en els dos primers documents

${ }^{58} 698$.
} del volum. 
en les societats i comandes. En molts d'aquests casos la relació dels documents amb negocis ultra-marins en terres mussulmanes és explícita ${ }^{59}$.

Tot plegat, doncs, delimita amb suggerent precisió l'àmbit principal d'ús dels besants, vinculats especialment amb negocis comercials i mercantils de llarg abast, molt més que els morabatins que malgrat ser moneda forastera, en ser castellana en certa manera no resulta tan exòtica i és emprada en més àmbits de relació i transacció local.

El valor de les quantitats en besants va de 300 besants en un debitori i la subsegüent liquidació de comptes ${ }^{60}$ a 1 besant en un cens per unes cases a Mallorca ${ }^{61}$. La relació entre els valors extrems és de 1 a 300.

\subsection{Masmudines}

Són tretze els documents d'ACF-1 que fan referència a quantitats de diner en masmudines. Els termes en què són esmentades són "mazemutinas", "mazemutinos in auro", "mazmudines", "mazemutinas auri fini rectique ponderis" i "mazemutinas in auro fino lucifias" (sic) ${ }^{62}$.

Es tracta de nou de moneda mussulmana, encunyada pels almohades. En set dels setze casos s'especifica que es tracta de moneda d'or, mentre que en els altres no s'especifica. De fet, ja des de principis del XIII es mencionen a Catalunya masmudines tant d'or com de plata ${ }^{63}$, però l'habitual sembla ser la d'or i cal considerar que és aquesta la que ens apareix ja que el fet que no s'especifiqui el contrari cal entendre que significa que es donava per sobre-entès el metall, que en absència de qualsevol referència a masmudines d'argent ha de ser l'or.

\footnotetext{
${ }^{59}$ Parlem, en l'apartat corresponent, dels debitoris en besants en què s'estableix que el pagament es farà a Cèuta $o \mathrm{a}$ Tunis, $\mathrm{i}$ el mateix es pot dir pel que fa a les àpoques $i$ societats i comandes. Així, els documents 67,130 i 387 fan referència a pagaments a Cèuta, els 274 i 297 fan referència a viatges a València, en domini encara islàmic, no cal dir; el 394 es remet a un pagament a Tunis, com també el 396, fet per la mateixa part. En el 373 s'obliga com a garantia un sarraí (i el 375 i 376 fan referència al mateix debitori), el document 563 és la cessió del lloc en la penyora de quatre sarraïnes, per la qual es reben 32 besants, el 869 és una procura sobre tretze sarraïns, en el 902 els 56 besants del debitori es comprometen a invertir-los en mercaderies a Tunis...

${ }^{60} 1412,1413$.

${ }^{61} 2889$.

${ }^{62} 746,1129$. La lectura és clarament aquesta.

${ }^{63}$ BotET I SISÓ, Les monedes, II, p. 34.
} 
A mitjan segle, a València es distingeix una masmudina "jucefina", de Iussuf, que seria pròpiament la mussulmana, i una masmudina "contrafacta" que seria la imitada. Equivaldrien a 6 sous i a 5 sous i 3 diners barcelonesos de doblenc respectivament ${ }^{64}$. Aquesta distinció no sembla tenir vigència al Vic de 1230-33, ja que no es percep una oposició entre tipus de masmudines sinó que les diferents formes en què són esmentades en els esborranys del manual semblen simple qüestió d'estil o d'obviació. Les masmudines de Vic del quart desenni del XIII serien amb seguretat masmudines mussulmanes de Iussuf, com ho confirmaria el qualificatiu de "lucifias", derivació anòmala del nom mussulmà ${ }^{65}$.

De les 13 vegades que a ACF-1 s'utilitzen masmudines, en sis casos és per establir censos en establiments -en cinc casos de terres i en el restant de cases $^{66}$-; Hi ha també dues àpoques $\mathrm{i}$ dos debitoris i una donació de deutes en diferents numeraris ${ }^{67}$. Un altre document és una comanda d'un fill en un viatge en què s'estableix que en arribar a Bugia aquest fill donarà, a aquell a qui es encomanat, "VIII macemutinos in auro" com a pagament; el darrer document és una constitució d'una societat ${ }^{68}$.

Esmentem el fet que en l'establiment del document 990 el cens es fixa en una masmudina menys sis diners de moneda de quatern ${ }^{69}$, estranya barreja de numeraris que tanmateix tampoc no dóna elements per a intuir l'equivalència més enllà de la simple constatació de l'ús dels diner de quatern com unitat pseudo-fraccionària de la masmudina.

Si bé com hem dit es tracta de moneda mussulmana, la seva funcionalitat resulta molt menys clara que en el cas dels besants, amb el problema afegit del nombre molt menor de referències. La moneda és vinculada en el cas de la comanda del fill, i possiblement també en la societat, la donació, les àpoques $\mathrm{i}$ els debitori, amb "negocis" o afers relacionats amb terra mussulmana, però els altres sis casos són censos d'establiments, la tipologia, ja ho hem dit, més inercial i continuïsta, fet que resulta aparentment

\footnotetext{
${ }^{64}$ Idem, p. 47.

${ }^{65} \mathrm{El}$ qualificatiu de "lucifias", que no admet altra lectura, seria una deformació de "iucifias", de Iussuf.

${ }^{66} 965,989,990,1836,2065,2299$.

${ }^{67} 602,746 ; 677,1129 ; 317$.

$68382,3144$.

${ }^{69}$ "Reddendo inde I mazemutinam omni tempore in festo Sancti Andree, minus VI denarios bone monete de quaterno, et nullum alium" (990).
} 
contradictori. Això faria pensar que es tracta d'un numerari amb suficient tradició, o implantació com per a haver passat als censos i amb un suficient valor i vigència a nivell exterior per ser emprada, encara que sigui de forma molt minoritària, en afers vinculats amb negocis ultramarins. És, en tot cas, una moneda present, disponible i utilitzable a Vic en el periode que tractem, encara que no deixa de ser moneda molt marginal, gairebé vestigial en tant que significa només un $0,6 \%$ de les referències a moneda del volum.

Encara que no tingui cap significat en tractar-se de tan poques referències, i encara que sigui com a simple curiositat, els valors que surten en masmudines van des del cens d'una masmudina menys 6 diners de quatern fins les mil masmudines d'un dels debitoris.

\subsection{Marcs d'argent}

Set són els documents en què s'esmenten marcs de plata: dos compromisos de pagament, un debitori, una cessió de lloc, una procura, una àpoca $i$ un rebut en societat ${ }^{70}$. Els documents parlen de "marchis argenti", "marchos argenti", i "marchas argenti". Els documents no tenen cap particularitat especial, i el valor més baix són els 3 marcs que junt amb 200 sous formen la comanda sobre la qual es fa la procura, mentre que el valor més alt són els "LII marchos argenti minus I uncia et dimidiam" que Ferrer de Cloquer reconeix rebre en societat junt amb 6.000 sous melgoresos i 20 marcs de moneda de quatern ${ }^{71}$.

El marc, ja ho hem dit més amunt, no és pròpiament una moneda real sinó una unitat de pes, base per a la talla de les monedes, que per extrapol-lació o per extensió passà a ser també unitat de compte, i en aquest sentit és equiparable a altres unitats que encara que són monetàries tampoc no tenen una existència real sinó que són també de forma exclusiva unitats de compte - sous, lliures-. En certa manera, fins i tot creiem més real com a unitat de pagament el marc d'argent que les unitats monetàries de compte ja que tampoc no ens sembla inversemblant que quantitats de certa entitat es poguessin fer efectives, si convenia, en funció del pes de plata en sentit estricte. El marc d'argent no sols s'utilitza de facto com una moneda i ens surt documentat únicament en aquesta funció sinó que ens sembla un mitjà

\footnotetext{
${ }^{70} 386,418,578,2055,2536,3074,3178$.

${ }^{71} 578,2536$.
} 
de pagament igualment vàlid, o més. Botet fixa el pes del marc de plata en 234,2734 grams per aquesta època ${ }^{72}$. El marc defineix la talla de la moneda en funció dels sous que s'encunyin amb cada marc de plata, i l'equivalència seria de 44 sous de quatern o 88 sous de doblenc.

\subsection{Millaresos}

Només en un document surt de forma aillada aquest tipus de moneda, concretament en una liquidació que Pere Ferrer fa de tota una comanda "preter XVI millarisios"73.

Si bé Botet i Sisó esmenta els millaresos al 1208 com identificables als besants de plata ${ }^{74}$, és clar que en aquest cas són unitats diferents. De fet, tal com hem esmentat en parlar dels besants, la manera com surten esmentats permet pensar que es tracta de moneda fraccionària dels besants, però sent aquesta l'única referència en que surten els millaresos de forma aïllada hem optat per a tractar-la a part. D'altra banda, si bé Jaume I va encunyar millaresos, sembla que les encunyacions són mès tardanes que l'època que estudiem $^{75}$, i en tot cas, per afinitat amb els millaresos que surten junt amb els besants també aquí es tractaria de moneda mussulmana.

\subsection{Rals coronats}

El novè i darrer tipus monetari que apareix a $A C F-1$ de nou en un únic document, són els rals coronats. En un debitori de 60 sous de doblenc que fa Arnau Vidal a Pere Ferrer fa constar que li ha pagat "X libras et

\footnotetext{
${ }^{72}$ BoteT I Sisó, Les monedes, II, p. 20, i p. 39. (La GEC el fixa en 237 grams, pes que Botet dóna al marc d'or de la mateixa ceca de Barcelona). Veure també Manuel RIU, De metrologia: la pensa, la lliura, el marc i l'unça, dins "Acta Numismàtica", 21-22-23 (1993), pp. 385-394.

${ }^{73} 1783$.

${ }^{74}$ BoTET y SISÓ, Les monedes, II, p. 34: "També's fa menció, en 1208, de bisancis de plata, als quals se dóna'l nom de millaresas".

${ }^{75}$ Botet (p. 52), en parlar d'encunyacions de moneda aràbiga de Jaume I fa referència a un document de 1225 relatiu a Lleida, però per la noticia que en dóna no sembla que es tracti d'encunyació sino d'us, sent així que la referència explícita a encunyació de millaresos se situa ja a 1258.
} 
dimidiam $\left\ulcorner\right.$ denariorum $_{\neg}$ de regalibus coronatibus $\ulcorner$ quos mihi mutuavistis apud Marciliam in carta $\neg$ preter ipsos LX solidos de duplo"76.

Es tracta de moneda de billó com el doblenc i el quatern, encunyada pels comtes catalans a Provença a finals del XII i primera meitat del XIII. La primera emissió la féu Alfons I a partir de 1186 i amb petites variants tipològiques hauria estat batuda també a principis i a mitjans del XIII ${ }^{77}$. Com es veu, en l'únic cas que apareix a la documentació vigatana de 12301233 és relacionada amb un préstec fet precisament a Marsella.

\subsection{Conclusió de la revisió dels tipus de moneda}

En resum, de la revisió del panorama monetari dels primers anys de la quarta dècada del segle XIII el que es dibuixa com a tendència clara, pel que fa a l'ús i freqüència relativa de les diferents unitats monetàries, és el clar -i també d'altra banda lògic- predomini de la moneda barcelonesa de doblenc, al capdevall la moneda "oficial" de la corona, però que coexisteix amb la presència, encara que minoritària, d'altres numeraris fins a un total de nou monedes amb presència simultània, vuit si considerem els millaresos com a fraccionaria dels besants. Aquestes altres monedes minoritàries suposen una part significativa i no negligible ja que al capdevall recullen en conjunt un $17,5 \%$ de les referències a moneda.

D'aquestes monedes secundàries es pot distingir per una banda una "bona moneda de quatern", moneda pròpia però oficialment anacrònica, que coexisteix en transaccions i actes diversos però de manera vestigial i amb especial pes en les tipologies més continuïstes, i per altra banda hi hauria els diversos tipus de moneda estrangera o "internacional".

Dins aquesta moneda estrangera cal distingir bàsicament entre dos blocs.

Per una banda, un bloc de moneda d'abast més curt, en el que hi hauria la moneda melgoresa i els morabatins. La moneda melgoresa al capdevall és mig moneda pròpia per tal com té el focus a la ciutat de Montpeller, domini de Jaume I. Els morabatins, malgrat ser moneda estrangera s'usen en nombrosos documents d'ambit local (censos, esponsali-

\footnotetext{
${ }^{76} 1335$.

${ }^{77} \mathrm{Cf}$. Miquel Crusafont i SABAtÉ - Anna M. Balaguer, Els comtats catalans: les seves encunyacions $i$ àrees d'influència, "Symposium Numismatico de Barcelona", 1979, p. 453, 455, 461 .
} 
cis,...) i no tenen, en principi, una molt clara diferència en la funcionalitat o en l'especialització quant al seu ús sinó que surten en tipologies documentals prou variades, mentre que en la moneda melgoresa la diversitat tipològica no és tan gran (recordem l'anormalment alt percentatge en els debitoris i sobretot en les societats i comandes), però no hi ha referència a comerç de llarga distància sinó que segueix movent-se en un àmbit que no depassaria grosso modo els dominis de la corona catalana. A aquest grup caldria incorporar-hi també, és clar, l'única referència als rals coronats provençals.

Per altra banda, com a segon bloc de monedes estrangeres hi hauria les diverses monedes mussulmanes - sobretot els besants-, que si bé en alguns casos es fan servir en tipologies documentals prou diverses el cert és que tenen un rotund predomini, com és lògic, en les transaccions o negocis relacionats amb el comerç, bàsicament marítim, internacional. Dins aquest grup hi hauria sobretot els besants, amb els millaresos, i les masmudines, encara que en tots els casos el seu ús no és exclusivament en aquest tipus de transaccions sinó que s'empren també de forma més o menys esporàdica en transaccions o negocis locals, especialment, ja ho hem dit, les masmudines.

Un cas a part serien les referències a marcs d'argent. En principi no es tracta d'una unitat monetària sinó de pes i, en tant que pes en plata és una "moneda" dotada de valor objectiu, i funcionalment podria fer la mateixa funció de les monedes de curs internacional.

\section{EQUIVALÈNCIES MONETÀRIES}

Un dels problemes principals en la moneda medieval és establir les relacions entre els diferents numeraris, les equivalències monetàries. Sense tenir elements per a relacionar els valors en diferents numeraris resulta impossible relacionar quantitats i interpretar l'entitat de les transaccions, i tanmateix resulta notablement inhabitual poder gaudir d'equivalències explícites per moments concrets.

Les equivalències són difícilment extrapolables o extensibles a èpoques diferents, ni que siguin properes, ja que poden variar de forma sensible en 
lapses petits de temps ${ }^{78}$, i per això, qualsevol referència a equivalències, escadussera que sigui, és d'un màxim interés.

Quines són les equivalències que dóna o aporta $\mathrm{ACF}-1$ de les monedes que hem vist?

No són molts els documents en què hi ha elements que es puguin considerar equivalències monetàries.

El primer cas és el document 1626, de 23 de març de 1232: "Berengario de Cheralto debeo tibi Guilelmo de Boxo D solidos de duplo vel CCCLX solidos malguirienses". Les paraules "vel CCCLX solidos malgurienses", que apareixen interliniades, podrien considerar-se de manera estricta com una equivalència entre ambdues quantitats. El valor que resultaria seria 1 sou melgorès $=1,388$ sous de doblenc. En aquest cas no es tractaria d'un canvi establert de forma oficial sinó del canvi de mercat, i el valor resultaria lleument més elevat que el canvi oficial que hem vist per quinze anys més tard i a València.

Tenim una altra equivalència entre moneda melgoresa $\mathrm{i}$ doblenc barceloní al document 2297, un debitori de 10 de gener de 1233: "Berengarius de Merles, vicensis canonicus debeo tibi Ferrario de Birgi $<$ dano $>$ et cui < velis > LXXXV solidos de duplo, pro quibus obligo tibi et cui $<$ velis > totam annonam cabiscolie minoris quousque de dictis denariis sitis paccatus. Et hoc iuro ego dictus Berengarius atendere, et valent malguirienses XVI cum barchinonensibus". L'equivalència només es pot entendre com que 1 sou o 12 diners melgoresos equivalen a 16 diners de doblenc, cosa que dóna una relació de $1=1,333$.

\footnotetext{
${ }^{78}$ Algunes referènciea a equivalències monetàries són ja clàssiques. És el cas de l'usatge Solidus aureus [Ramon d'ABADAL I VINYALS - Ferran VALLS TAVERNER, Textes de Dret Català. I: Usatges de Barcelona, Barcelona, 1913, pp. 64-65, usatge 141. Aquest usatge no és recollit en l'edició crítica de Joan Bastardes (Usatges de Barcelona. El codi a mitjan segle XII, Barcelona, 1984), si bé hi és esmentat com a tal (p.27)]. La refèrencia a mancusos ja indica que l'equivalència cau lluny del marc cronològic on ens movem, i pels valors i les monedes sembla que cal situar els valors, i l'usatge, ben bé al segle XI. Així, l'equivalència de 7 mancusos amb una unça segons Botet i Sisó (La moneda, vol. I, p. 43) seria vigent entre els anys 1052 i 1072 mentre que segons A. M. Balaguer es donaria sols en els encunyats per l'orfebre jueu Bonhom, entre 1017 i 1035 . A partir de 1037 el pes baixa fins a 10 mancusos per unça. (Diccionari d'Història de Catalunya, Barcelona, 1992, vide sub "mancús"). També clàssiques són les nombroses equivalències que dóna Botet i Sisó entre les quals per proximitat citem les equivalències fixades en la taula de canvi a València el 1246 (BOTET I SISÓ, Les monedes, vol. II, p. 47). Reduint i simplificant les equivalències que dóna, les que ens interessen serien: 8 diners melgoresos $=9$ diners barcelonesos; 1 morabatí alfonsí $=9$ sous barcelonesos; 1 masmudina jucefina $=6$ sous barcelonesos; 1 ral de Marsella $=0,75$ diners barcelonesos.
} 
Tenim també una equivalència entre doblenc i besants, al document 1698, una àpoca feta a un nombre incert de les kalendas de juny de 1232: "Legetus de Seva recognosco et fateor tibi Petro de Granario quod recepi et habui a te L solidos quod mihi debebat Bernardus de Graner frater tuus in carta quam tibi trado in presente, renunciando omni excepcione. Solvendo $<$ et cetera $>$. Manifestum est enim quod quantum persolivisti mihi illud debitum tunc valebat bisancium $V$ solidos et III denarios". Quan li va pagar el deute el besant valia 5 sous i 3 diners òbviament de doblenc. El fet que es precisi que era el preu que valia aleshores pot fer pensar que no sigui l'equivalència vigent a l'hora de redactar l'àpoca.

És igualment una de sola l'equivalència que ens dóna el volum entre els morabatins i la moneda de doblenc. Al document 2910, de 13 de juliol de 1233, Garsenda vídua de Guillem de Montcada reconeix a Arnau de Santa Cecília que li ha passat comptes de tots els deutes que li debien, a ell, Guillem Ramon de Montcada i el seu fill Guillem de Montcada i que ella li devia per raó d'ells. Fa constar que "facto computo sunt MMMD solidos de duplo quod tibi persolvimus eos in primis pagis nobis donas et dimitis $\mathbf{M}$ solidos in presenti, et ita remanet ad persolvendum MMD solidos de duplo, de quibus, factis morabatinis, sunt CCXXVIII morabatinos quos convenimus persolvere in primis pagis que fecerint de debitis et iniuriis dicti Guilelmi de Montecatano, super res nostras"; queden per pagar 2.500 sous de doblenc, que en morabatins són 228. Un morabatí seria per tant equivalent a 10,9649 sous de doblenc, és a dir, 11 sous.

Finalment tenim dues equivalències entre marcs d'argent i moneda de quatern, o més aviat dues versions d'una mateixa equivalència ja que es tracta de dues versions d'un mateix compromís de pagament. Al document 3074 de 2 de setembre de 1233, ratllat en la seva primera meitat però barrat, Guillem de Vic convé i promet a Bernat Fi "XI marchos argenti quod ego persolvam tibi pro illis DL solidis bone monete de quaterno... quos tibi debeo persolvere". El document es devia anular perquè a finals d'octubre de 1233, document 3178, Guillem de Vic de nou convé i promet a Bernat Fi "quod ego persolvam tibi XI marchas argenti vel denarios qui eis valeant, pro ipsis scilicet DL solidis bone monete de quaterno quos tibi debeo persolvere". Curiosament, i ben interessantment, la relació que es desprèn dels dos documents no és la relació oficial de talla de la moneda de quatern, de 44 sous per marc de plata, sinó de 50 sous per marc. Pel doblenc tenim en canvi documentada explícitament al volum la mateixa equivalència de talla: "XII denarios monete de duplo velentis marcam argenti LXXXVIII 
solidis" (552), "MCC solidos monete de duplo, valentis marcham argenti LXXXVIII solidos" (1697), "MCXX solidos de duplo, valente marcha LXXXVIII solidos" (1891),...

Resumim en un quadre, ja per acabar, les poques, però per l'època sempre valuoses, equivalències monetàries que ens proporciona el volum:

\begin{tabular}{||l|l||}
\hline $\begin{array}{l}\text { uúm. de } \\
\text { document (si- } \\
\text { tuació a } \\
\text { ACF-1) }\end{array}$ & equivalència \\
\hline $1696(104 \mathrm{v}-1)$ & 1 sou melgorès $=1,388$ sous de doblenc. \\
\hline $\begin{array}{l}2297(137 \mathrm{v}- \\
11)\end{array}$ & 1 sou melgorès $=1,333$ sous de doblenc. \\
\hline $1698(104 \mathrm{v}-3)$ & 1 besant $=5$ sous i 3 diners de doblenc. \\
\hline $2910(176-7)$ & 1 morabatí $=10,9649$ sous de doblenc. \\
\hline $3074(187-6)$ & 1 marc d'argent $=50$ sous de quatern. \\
\hline $3178(192 \mathrm{v}-3)$ & 1 marc d'argent $=50$ sous de quatern. \\
\hline
\end{tabular}

\section{RÉSUMÉ}

Si normalement on étudie la monnaie médiévale dès le point de vue numismatique ou comme un instrument ou un élément de fiscalité ou de rente des pouvoirs publics qui la frappent, cette étude, qui part des références à monnaie dans la documentation notariale et très particulièrement dans le premier volume des Arxives de la Cúria Fumada de Vic (3.308 documents de la période de septembre 1230 à décembre 1233), analyse la monnaie qui circule reélement dans la Catalogne intérieure pendant la première moitié du XIIIe. siècle, en documentant jusqu'à neuf numéraires simultanés différents. L'étude analyse les différentes monnaies, leur importance relative, leurs enceintes d'usage, leur spécialisation et leurs équivalences. L'étude apporte aussi de nouvelles données à l'aspect ponctuel des frappes de monnaie épiscopale de Vic à la première moitié du XIIIe. siècle. 


\section{SUMMARY}

While medieval coinage is normally studied from a numismatic point of view or as a fiscal instrument or element of income for the public authorities responsible of the coinage, this study, considering the references to different currencies in notarial documentation and especially in the first volume of the Cúria Fumada archive of Vic $(3,308$ documents covering the period September 1230 to December 1233), analyses the monetary types wich were really in use in the interior of Catalonia during the first half of de XIII century, documenting up to nine simultaneous different currencies. This study analyses the different currencies, their relative importance, their ambit of use and their specialisation and equivalencies. New information is also provided regarding a particular subject as is the episcopal stamping of coins in Vic during the first half of the XIII century. 